\title{
Nonperforming Debts in Chinese Enterprises: Patterns, Causes, and Implications for Banking Reform*
}

Geng Xiao
The University of Hong Kong
Hong Kong, SAR, China
xiaogeng@hku.hk

\begin{abstract}
Given the domination of bank financing, nonperforming debts (NPDs) in large Chinese enterprises are a proxy for nonperforming loans (NPLs) in China's major banks. Using a firm-level survey of more than 20,000 large and medium-sized industrial enterprises conducted by the National Bureau of Statistics of China, this paper estimates both the level and ratio of NPDs across ownership type, industry, and region for the period 1995-2002. The results show that NPD ratios have been falling since 2000 as a result of the rapid expansion of better-performing non-state enterprises (NSEs), the improved performance of state-owned enterprises (SOEs), and the exit of poor-performing enterprises (which has been facilitated by asset management companies and other merger and acquisition activities). SOEs, however, are still much more likely than NSEs to generate NPDs. This paper provides useful tools and sector information for assessing enterprise debt risks and draws lessons for banking reform in China.
\end{abstract}

\section{Introduction}

Since early 2004, the newly established China Banking Regulatory Commission (CBRC) has announced quarterly

* This paper was presented at the Asian Economic Panel meeting in Hong Kong on 12-13 April 2004, and at the Hong Kong Monetary Authority workshop on 8 July 2004. The author would like to acknowledge research collaboration with the Industry and Transportation Department of the National Bureau of Statistics (NBS) of China. Xing Junling and Yu Xiaoyun provided extensive technical support at NBS. Tu Zhengge provided excellent research assistance. The author would like to thank the Research Grant Council of Hong Kong and the University Grant Council of Hong Kong for financial support (project nos. HKU7167/98H

1 LINE SHORT and $\mathrm{AOE} / \mathrm{H} 05 / 99$ ). This research work also benefited from a

REGULAR

1 LINE LONG

(C) 2006 The Earth Institute at Columbia University and the Massachusetts Institute of Technology

Asian Economic Papers (ASEP) 4:3

Job No. 1055

page 61 
statistics on the ratio of nonperforming loans (NPLs) for China's major banking institutions. It reported a sharp decline in the NPL ratio from above 24 percent in 2002 to 19.6 percent in June 2003, 17.8 percent in December 2003, 13.3 percent in June and December 2004, and only 8.7 percent in June 2005. During the 2-year period between June 2003 and June 2005, the outstanding amount of NPLs in China dropped from RMB2.538 trillion to RMB1.276 trillion, a decrease of RMB1.262 trillion. This is clearly a dramatic turnaround in terms of banking sector performance. Are the official statistics reliable? What happened to the quality of bank loans and debt in China's enterprises? These questions motivate this paper. Outside observers interpreted the official reports cautiously because they did not understand how China's banks calculated their NPL ratios. Most analysts and commentators would still estimate China's NPL ratio to be at a much higher level than the official figure-usually two to three times that of the official NPL ratio. For example, UBS, an investment bank and global asset management firm, (Anderson 2005) estimates that China's NPLs fell from about 50-55 percent in 1997-98 to about 25-30 percent by the end of 2004. These market estimations of NPL ratios are usually based on macroeconomic data because it is difficult to get reliable and representative microeconomic data from Chinese banks.

This paper attempts to develop an alternative approach to the study of NPLs in China using firm-level microeconomic data. As a result of the limited development of stock markets and enterprise bond markets in China, banks are still the major holders of enterprises' long-term and short-term debt. In recent years, Chinese banks have expanded rapidly in the business of consumer loans, especially mortgage loans. The outstanding amounts of consumer loans rose from below 1 percent in 1998 to above 10 percent in 2004. Because the quality of consumer loans is generally much better than that of enterprise loans, the quality of bank loans depends largely on the quality of the bank lending to enterprises. The quality of enterprise debt is directly linked to the profitability of the enterprises. The ability to pay the interest and principal of loans derives ultimately from profitability and cash income flows of the enterprises. This is especially true if we are examining a large group of enterprises, in which the variations in the enterprise-specific timing of cash income flows and the structures of financing within the group will be averaged out statistically through the law of large numbers, making the profitability of each enterprise

seed fund for strategic research in corporate and financial law and policy from The University of Hong Kong. The author is also grateful to Wing Thye Woo, Dwight Perkins, Jeffrey Sachs, Alan Siu, Richard Wong, Sung Yun Wing, Zhang Weiying, Erh-Cheng Hua, Ren Ruoen, Peng Wensheng, and Guonan Ma for comments and suggestions. The author takes responsibility for any errors. 
the single most important contribution to the quality of the enterprise group's portfolio of debts.

This paper uses the profitability conditions of each enterprise to measure and characterize the quality of the enterprise group's portfolio of debts. It uses both reported profitability and imputed profitability (the latter is derived from the components of value-added) to give two alternative estimates of the quality of debt portfolios for different groups of enterprises classified by ownership, industry, and region. The method is applied to a comprehensive annual survey of all the large and mediumsized industrial enterprises in China conducted by the National Bureau of Statistics of China. Information about the survey data can be found in tables A.1 to A.6 in the appendix. The survey sample includes more than 20,000 enterprises and covers the period from 1995 to 2002 (see table A.6). In 2002, the sample enterprises had 26 million employees in total, which is about 16.7 percent of China's total industrial employment. These enterprises incurred RMB5.7 trillion in debt, an amount equal to 43.6 percent of the total loans in China's financial institutions. The sample enterprises contributed about 19.2 percent of China's GDP. Clearly these enterprises are the most important leaders in the Chinese industrial sector. Aggregate financial information about the sample enterprises has been regularly reported in the Statistical Yearbook of China.

The contribution of this paper is the methodology of using the disaggregated firmlevel data to study the enterprise profitability of the enterprises and the quality of their debts. The paper derives both the level and ratio of NPD across enterprise groups by ownership, industry, and region for the period 1995-2002. The results show that NPDs have indeed been falling as a result of both the rapid expansion of better-performing non-state enterprises (NSEs) and improvements in the performance of state-owned enterprises (SOEs), as well as rapid exit of poor-performing state-owned enterprises, which has been facilitated by newly established asset management companies that specialize in dealing with NPLs. The micro-level evidence uncovered here is largely consistent with the CBRC reports on falling NPLs and NPL ratios in China's banking sector. This study, however, provides a more transparent, simpler, and more objective method of estimating NPDs and allows outsiders to examine the detailed causes and dynamics of the changing patterns of NPDs in Chinese enterprises. In particular, it was found that the SOEs had consistently generated higher NPD ratios than the NSEs, providing a challenge as well as an opportunity for future banking reform.

Section 2 defines our concepts of NPDs; section 3 shows the patterns of NPD and NPD ratios across enterprises' ownership type, industry, and region; and section 4 
examines the trend of NPD ratios during the period 1995-2002 and provides scenarios of the future of NPD ratios in China. Section 5 uses panel data regressions to identify the impacts of various factors on the profitability and debt quality of the enterprises. Section 6 addresses the sample-selection bias in the measure of NPD ratios resulting from the exit of poor-performing enterprises from the sample over the study period. Section 7 discusses the implications of the empirical results for banking reform in China.

\section{Defining and estimating NPDs}

In recent years, the CBRC has been trying hard to monitor and supervise the NPLs in China's banking institutions. It developed detailed rules on the reporting of the amount of NPLs and the NPL ratios. The purpose is to manage and reduce financial risk by monitoring both the changing distribution of NPLs and the changing NPL ratios of individual banks and bank branches. This is clearly necessary and useful. Poor governance of banks is a sufficient condition for creating NPLs, even when the enterprise sector is doing well.

The efforts of the CBRC and the individual banks to reduce NPLs, however, are only necessary conditions. Ultimately, the quality of China's banking assets and enterprise debts depends directly on the profitability of China's enterprises. For example, in the short run it is easy for banks to reduce NPL ratios, or even the amount of NPLs, by simply expanding the total amount of loans. New loans are much less likely to have repayment problems in the short run, but they could create more bad loans in the future if they are extended to potentially loss-making enterprises. New loans can help existing loss-making enterprises continue to pay their interest on old loans, thereby also shifting the underlying risks to the future. The problem is especially serious when the economy is booming. These are the main reasons why the reliability of NPL statistics as reported by China's banks can vary considerably, depending on how they are calculated. Outsiders are unable to completely understand how the NPLs and NPL ratios in China's banks are actually calculated because the decisions in each individual case require judgments that are too complex for outsiders to assess. This is why analysts and commentators rely more on the study of China's macroeconomic conditions, such as business cycles and sector performance, to gauge the level of NPLs in China. Based on their personal impressions and understandings about the Chinese economy, they report NPL ratios that are usually two to three times larger than the official ratio.

1 LINE SHORT

REGULAR

1 LINE LONG
This paper attempts to develop an objective measure of the quality of enterprise debts in China. Profitability is the only criterion used in measuring the quality of these debts. The concept and its implementation are straightforward. If the enter- 
prises are making profits, the quality of their debts (more specifically their total liabilities) are termed "performing." If they are making losses, their debts are regarded as "nonperforming." The amount of NPD for a specific enterprise group is then the sum of the total liabilities in the loss-making enterprises for that group. The NPD ratio for the group is simply the ratio of the sum of total liabilities in the loss-making enterprises divided by the sum of total liabilities in both the loss-making and profitmaking enterprises in the group. These simple definitions of NPD and the NPD ratio make our NPD statistics objective, easy to measure, and easy to understand.

Our concept of the NPD ratio, however, is not applicable to an individual enterprise, because according to our definition, an enterprise cannot have part of its total debt be performing and the other part be nonperforming: all the debts in any given enterprise have the same quality. For instance, one enterprise cannot have 70 percent of its debts performing and 30 percent nonperforming. For an individual enterprise, losses might occur in the first few years, but the firm would make profits in the future. After a close examination by its creditors, such a firm would be considered to have high-quality debt. Our definition of NPD would not be fair to this particular enterprise. On the other hand, a currently profitable enterprise might become a loss maker. Then its debt quality would be bad upon close examination. Our assessment, based only on current profitability, might not do justice to this particular enterprise. The difference between current profitability and longer-term profitability, however, could be seen as a random distribution for a large group of enterprises, such as groups in our sample separated by time, ownership, industry, and region. With a sizable group, the variability in the timing of cash flows, profit streams, payments to creditors, and other profitability-related variables for enterprises within the group would offset each other, leaving the average NPD ratio for the group a much more reliable and accurate measure of the quality of the group's portfolio of debts. This is why our concept of the NPD ratio is useful only for measuring debt quality for groups of enterprises. This study would be very useful as complementary research to the traditional method of estimating NPLs.

For our method to be useful, it needs to be applied to a representative sample with sizable groups of enterprises. The annual survey of large and medium-sized industrial enterprises conducted by China's National Bureau of Statistics (NBS) is a suitable data set for our method. The NBS data are in fact census data, not really sample data, because the survey covers all large and medium-sized industrial enterprises in China. In 2002, China had more than 180,000 industrial enterprises with sales above RMB5 million. The NBS sample includes only about 21,000-23,000 large and medium-sized industrial enterprises out of a total of 180,000 firms. Many small industrial enterprises are not included in our study, but most of them have limited access to bank finance under the current financial system in China.

1 LINE SHORT

REGULAR

1 LINE LONG 
One major weakness of using our method for the NBS data is sample selection bias. The group of enterprises included in the NBS survey each year is not always the same. About 20 percent of the group consists of enterprises that enter and exit the survey sample each year as a result of changes in their size classification or organizational changes such as mergers and acquisition, privatization, reorganization, and bankruptcy. The profitability of exiting firms is not necessarily the same as that of the new entries. This means that we are studying only the largest and most dynamic frontier industrial enterprises in China and leaving out the poor-performing ones. We will address this issue in section 6 and show the impact of this sample selection bias on the estimated ratio of NPD.

Our sample covers not only SOEs but also other types of enterprises in all industries and regions, including rural and urban collectives, private enterprises, domestic mixed-ownership corporations, foreign-invested enterprises, and enterprises with investment from Hong Kong, Macau, and Taiwan. Our sample does not include nonindustrial enterprises, however, such as China Telecom, a big service sector firm. It is entirely possible that the enterprises not included in our sample have worse performance records than the enterprises in the NBS sample. If that is the case, the NPD ratios for the entire Chinese enterprise sector would be higher than the ratios reported in this study. Also, if the banking institutions in China are performing worse than the enterprises in the NBS sample, as a consequence of their own weak governance, the overall NPL situation of the Chinese economy as a whole would be worse than that for the sample enterprises used in this study. In addition, we cannot directly compare the NPL ratios reported by the CBRC with the NPD ratios estimated in our study because they are defined differently. The NPD ratios here are designed to examine the trend and the cross-sectional patterns of the quality of Chinese enterprise debts.

During the period from 1995 to 2002, the sample enterprises created about 16-25 percent of China's industrial employment and 33-43 percent of China's industrial value added (see table A.6). Most significantly, the sample enterprises contributed about 14-19 percent of China's GDP. Their total liabilities, one of the key variables we examine in this paper, amount to about 43-65 percent of China's total banking loans during the 1995-2002 period. Of course, not all of the total liabilities in the sample enterprises correspond to loans from banks. But even assuming that 60 percent of the total liabilities in the sample are related to various bank loans, the statistical analysis in the paper provides an in-depth study of the quality of about 27-29 percent of China's total loans. In summary, although the members of the sample enterprises group are changing each year, as a whole they form a stable club of China's elite industrial enterprises. The performance of this elite group of enterprises is 
much more representative of the performance of China's industrial economy than, for example, the performance of China's listed companies or any small sample of Chinese enterprises. Given the growing importance of China's industrial sector for both the domestic and global economy, our analysis in this paper fills a crucial gap in understanding the dynamics of China's industrial reform and development.

Tables 1, 2, and 3 show the distribution of the total liabilities for the sample enterprises by ownership, industry, and region. The objective is to find out how much of these debts are located in profit-making and loss-making enterprises and then calculate the amounts and ratios of the NPD. There are two underlying forces affecting the NPD ratios: the shifting distribution of debts across enterprise groups with different profitability and the changing profitability of each group.

Table 1 shows the distribution of total liabilities (or total debts) across ownership types. The share of total debts by SOEs fell sharply, from 76.4 percent in 1995 to 48.2 percent in 2002, to the benefit of domestic mixed-ownership corporations and private enterprises. The total debt for SOEs increased from RMB2.5 trillion in 1995 to RMB3.2 trillion in 1998, immediately before the Asian financial crisis, and then fell to RMB2.8 trillion in 2002. The total debt for collectives followed the same pattern as that for SOEs, rising from RMB227 billion in 1995 to RMB287 billion in 1998 and then falling to RMB219 billion in 2002. The shifting of debt toward private, mixed, foreign, or overseas Chinese enterprises was steady and rapid throughout the 19952002 period, without any interruption resulting from the Asian financial crisis in 1998-99. For the 8 years from 1995 to 2002, total debt in the sample enterprises increased by RMB2,436 billion. Of this net increase, RMB246 billion ended up in the SOEs, RMB1,411 billion went to mixed-ownership enterprises, RMB467 billion to foreign enterprises, and RMB95 billion to private enterprises. The drastic changes in the distribution of total debt are strong evidence of the rapid but quiet privatization and opening up of the most dynamic part of China's industrial sector. In the next section, we will show that the redistribution of total debt from SOEs toward the better-performing NSEs contributed to the larger part of the observed fall in average NPD ratios for the sample enterprises.

How were financial resources allocated among the Chinese industrial enterprises during 1995-2002, which can be characterized as a period of high growth and steady reform? Which industries and regions were getting more financial resources for their elite industrial enterprises? Tables 2 and 3 provide the answer. The two tables give us detailed information about credit allocation among China's large and mediumsized industrial enterprises and illustrate the changing landscape of Chinese enterprise financing. In tables 2 and 3 the total debt for each industry or region are sorted 
Nonperforming Debts in Chinese Enterprises

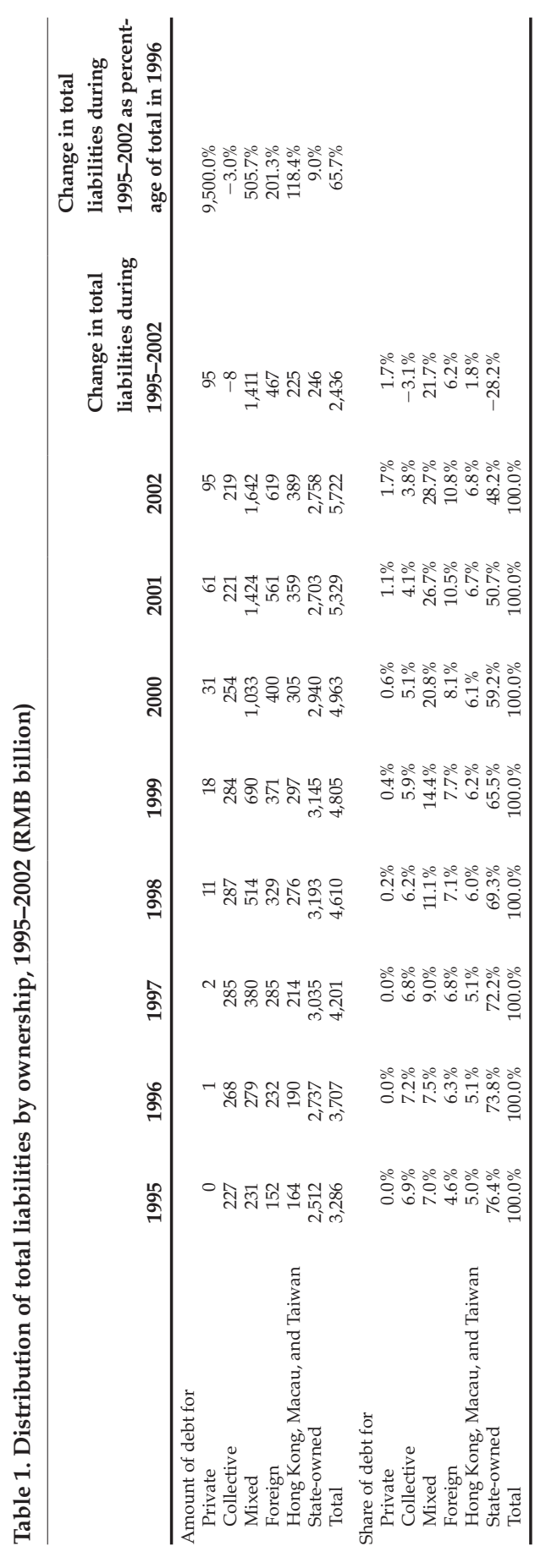

REGULAR

1 LINE LONG 
by their amount in 2002, to make it easy to look for the winners and losers. The last two columns show the amount of change and the growth rate for total debts during the 1995-2002 period.

As shown in table 2, the top five industries in 2002, ranked by the level of their total debts, were electric power, steam and hot water; transport equipment manufacturing; smelting and pressing of ferrous metals; electronic and telecommunications equipment; and raw chemical materials and chemicals. The top five industries together attracted RMB2.692 trillion in debt, or 47 percent of the total debt for the whole sample. The net gains in debt for the top five industries during 1995-2002 amounted to RMB1.465 trillion, or 60 percent of the gains by the whole sample. China's financial risks are heavily influenced by the performance of the above five sectors.

From the last column of table 2, the top five industries ranked by the growth of their total debts during 1995-2002 were tap water production and supply; electric power, steam, and hot water; electronic and telecommunications equipment; papermaking and paper products; and gas production and supply.

Clearly, the above leading industries, which have attracted investment in the last decade, are largely related to industrial infrastructure, intermediate inputs, raw materials, production equipment, and utilities. Rapid development of these industries would lay a solid foundation for China's further industrialization. In this sense, China's enterprise finance looks increasingly driven by market forces. Of course, a risk-based regulation strategy would require extra attention to be paid to the sectors with heavy concentrations of investment. As we will see in the next section, some of the above sectors with rapid growth in enterprise debts do have high NPD ratios, especially the SOE-dominated utilities sector.

From table 3 we see that the top five regions ranked by the level of their total enterprise debts in 2002 are Guangdong, Jiangsu, Shandong, Shanghai, and Liaoning. These regions are clearly becoming China's new industrial centers. In section 5, we will examine region-specific enterprise performance, which is relevant for assessing debt risks across regions. Xiao (2005) examines enterprise performance in the northeast region of China in detail, and Xiao and Tu (2005) study China's industrial productivity growth using the same set of data.

In the next section, we will show how much of the total debt shown in tables $1-3$ is located in loss-making enterprises. Profitability of enterprises becomes the crucial variable for our study. Reported profits, however, present several problems. First, it 
Nonperforming Debts in Chinese Enterprises

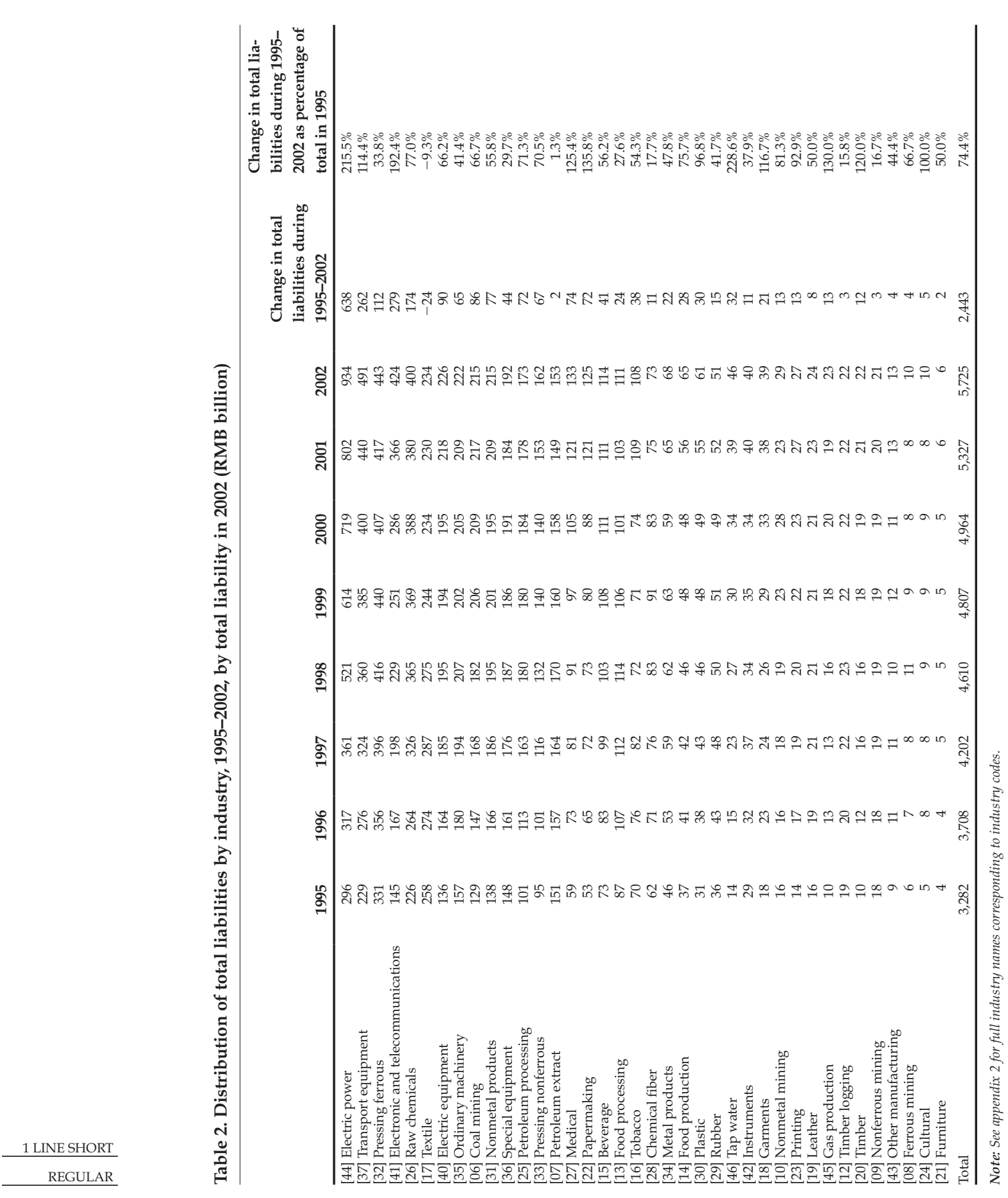

Asian Economic Papers

Asian Economic Papers (ASEP) 4:3 Job No. 1055 page 70 
Nonperforming Debts in Chinese Enterprises

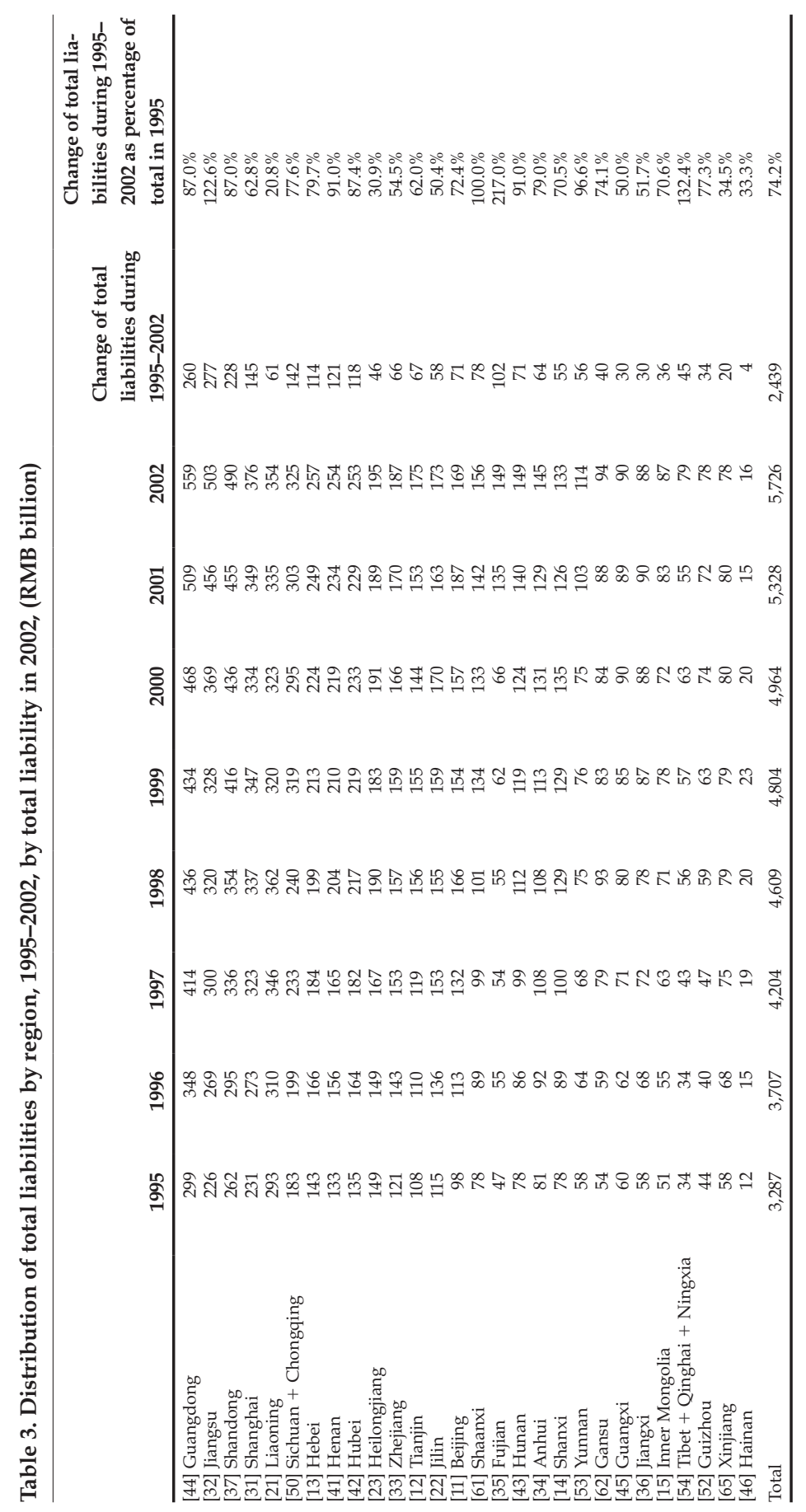

1 LINE SHORT

REGULAR

1 LINE LONG

Asian Economic Papers

Asian Economic Papers (ASEP) 4:3

Job No. 1055

page 71 
is difficult to check the consistency of reported profits with enterprises' other financial variables because of China's complicated accounting regulations. In other words, we do not know how reported profits are calculated from other financial variables reported in the NBS survey. Second, it is widely reported that enterprises sometimes manage their profit numbers for many purposes, including legal or illegal tax evasion. For this paper, it seems useful to develop an alternative measure of profitability, one that is based on a consistent set of financial variables available from the NBS survey. Because the main purpose of the NBS survey is to calculate the value-added of industrial enterprises, it is possible to develop a measure of an enterprise's profitability or potential profitability based on the reconstructed components of its value-added.

We use the following variables available from the NBS survey to define the imputed profitability of the sample enterprises:

$V A=$ value-added, including value-added taxes and financial changes

$W=$ wages and other employee compensation expenses

$F C=$ financial charges, mainly interest payments

$D=$ current depreciations

$T=$ all tax payments, including those for value-added taxes

$\mathrm{TA}=$ total assets

We can classify enterprises into eight profitability groups:

$[-4]:$ if $V A \leq 0$

[-3]: if $V A-W \leq 0$ and $V A>0$

[-2]: if $V A-W-F C \leq 0$ and $V A-W>0$

$[-1]$ : if $V A-W-F C-D \leq 0$ and $V A-W-F C>0$

$[+1]:$ if $V A-W-F C-D-T \leq 0$ and $V A-W-F C-D>0$

[+2]: if $V A-W-F C-D-T>0$ and $(V A-W-F C-D-T) / T A \leq .05$

[+3]: if $(V A-W-F C-D-T) / T A>.05$ and $(V A-W-F C-D-T) / T A \leq .15$

$[+4]:$ if $(V A-W-F C-D-T) / T A>.15$

Table 4 shows the number of enterprises in each of the eight profitability groups over the period from 1995 to 2002 . This imputed profitability by group allows us to separate the NPDs into more disaggregated groups according to the qualitative and quantitative extent of loss making. Chinese banks are in the process of changing from four loan classification categories (normal, overdue, doubtful, and poor) to the international standard of five categories (normal, special mention, substandard, doubtful, and loss). Unlike the classification of bank loans, the profitability 
Nonperforming Debts in Chinese Enterprises

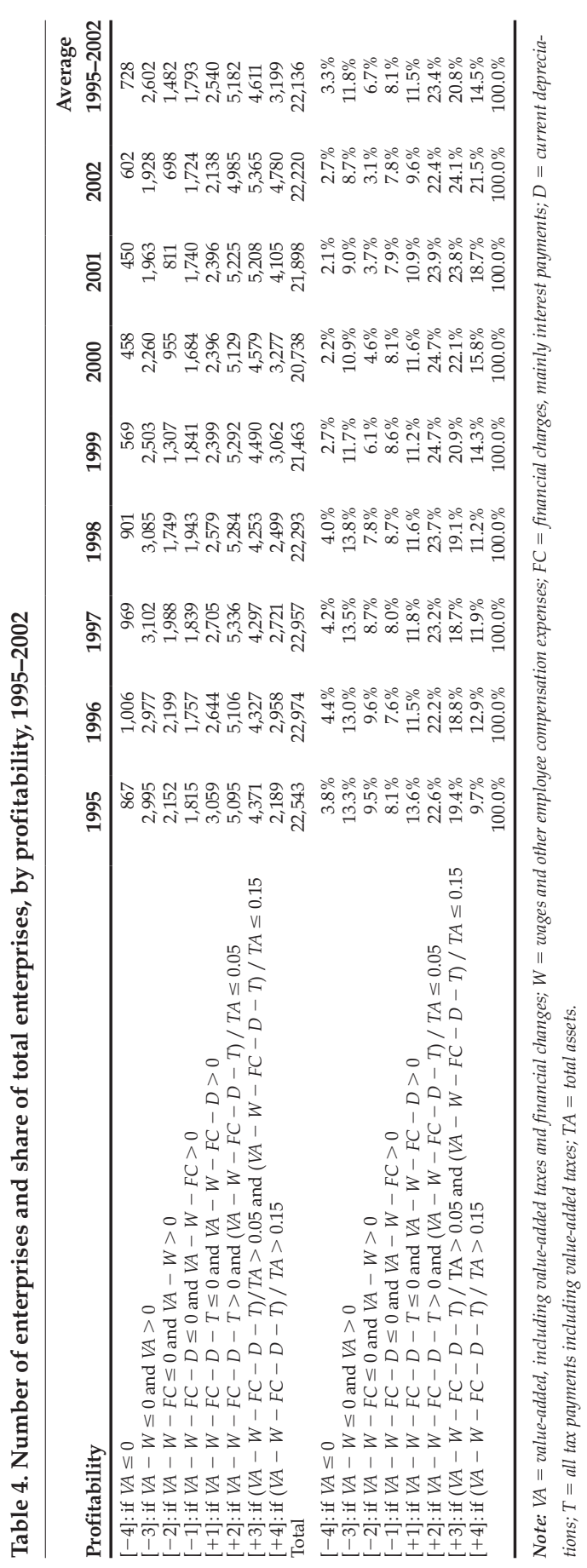


classification proposed here reveals the underlying economic conditions, for example:

- Enterprises in profitability group [-4] create negative value-added. They should be closed immediately according to economic principles. The quality of their debts is the worst among the eight groups by profitability.

- Enterprises in group [-3] have positive value-added but cannot pay all of their wage bills. In economics, they cannot even cover their variable costs. They should also be closed as soon as possible to avoid incurring new losses. The quality of their debts will worsen every day as the losses accumulate.

- Enterprises in group [-2] can pay their wage bills but cannot pay all of their financial charges. The quality of their debts is poor, but because their investment is sunk, such firms may have reasons to continue operations in the short run to maintain employment while waiting for a turnaround after reorganization.

- Enterprises in group [-1] can pay their wage bills and financial charges but cannot cover all of their depreciation charges. The quality of their debts will fall as capital is depleted.

We will leave the more detailed analysis of NPDs based on the above profitability classifications for a separate paper. Here we focus on the big picture first and classify enterprises in the first four groups as loss making and the last four groups as profit making, based on imputed profitability.

Table 5 shows the number of enterprises making profits or losses based on both reported and imputed profits over the period from 1995 to 2002. The number of lossmaking enterprises by imputed profitability was stable at about 8,000 (34-35 percent) during 1995-98 and fell rapidly afterward to 4,952 (22.3 percent) in 2002. The number of loss-making enterprises by reported profitability was 6,937 (30.8 percent) in 1995 and rose sharply to 8,987 (40.3 percent) in 1998, then dropped to 6,295 (or 28.3 percent) in 2002. In the next section, we will use both imputed and reported profitability to estimate the amount and ratio of NPD. Although the two profitability measurements are different in concept and measurement, both are useful for assessing the quality of enterprise debt. Imputed profitability is more useful for comparing enterprise performance across groups because it is based on a consistent set of reported financial variables, but it is different from actually reported profitability. Imputed profits can be larger than reported profits for several reasons. First, when output is not sold or is still in inventory, some of the value-added might not turn into actual profits. Second, reported profits are likely to be lower than imputed profits as a result of legal or illegal tax evasion or profit hiding. In other re- 
Nonperforming Debts in Chinese Enterprises

Table 5. Number and share of enterprises making profits or losses, 1995-2002

\begin{tabular}{|c|c|c|c|c|c|c|c|c|c|}
\hline & 1995 & 1996 & 1997 & 1998 & 1999 & 2000 & 2001 & 2002 & $\begin{array}{l}\text { Average } \\
\text { 1995-2002 }\end{array}$ \\
\hline \multicolumn{10}{|c|}{ Based on imputed profits } \\
\hline \multicolumn{10}{|c|}{ Number of enterprises } \\
\hline Making profits & 14,714 & 15,035 & 15,059 & 14,615 & 15,243 & 15,381 & 16,934 & 17,268 & 15,531 \\
\hline Making losses & 7,829 & 7,939 & 7,898 & 7,678 & 6,220 & 5,357 & 4,964 & 4,952 & 6,605 \\
\hline Total & 22,543 & 22,974 & 22,957 & 22,293 & 21,463 & 20,738 & 21,898 & 22,220 & 22,136 \\
\hline \multicolumn{10}{|l|}{ Share } \\
\hline Making profits & $65.3 \%$ & $65.4 \%$ & $65.6 \%$ & $65.6 \%$ & $71.0 \%$ & $74.2 \%$ & $77.3 \%$ & $77.7 \%$ & $70.2 \%$ \\
\hline Making losses & $34.7 \%$ & $34.6 \%$ & $34.4 \%$ & $34.4 \%$ & $29.0 \%$ & $25.8 \%$ & $22.7 \%$ & $22.3 \%$ & $29.8 \%$ \\
\hline Total & $100.0 \%$ & $100.0 \%$ & $100.0 \%$ & $100.0 \%$ & $100.0 \%$ & $100.0 \%$ & $100.0 \%$ & $100.0 \%$ & $100.0 \%$ \\
\hline \multicolumn{10}{|c|}{ Based on reported profits } \\
\hline \multicolumn{10}{|c|}{ Number of enterprises } \\
\hline Making profits & 15,606 & 15,088 & 14,476 & 13,306 & 14,328 & 15,144 & 15,510 & 15,925 & 14,923 \\
\hline Making losses & 6,937 & 7,886 & 8,481 & 8,987 & 7,135 & 5,594 & 6,388 & 6,295 & 7,213 \\
\hline Total & 22,543 & 22,974 & 22,957 & 22,293 & 21,463 & 20,738 & 21,898 & 22,220 & 22,136 \\
\hline \multicolumn{10}{|l|}{ Share } \\
\hline Making profits & $69.2 \%$ & $65.7 \%$ & $63.1 \%$ & $59.7 \%$ & $66.8 \%$ & $73.0 \%$ & $70.8 \%$ & $71.7 \%$ & $67.4 \%$ \\
\hline Making losses & $30.8 \%$ & $34.3 \%$ & $36.9 \%$ & $40.3 \%$ & $33.2 \%$ & $27.0 \%$ & $29.2 \%$ & $28.3 \%$ & $32.6 \%$ \\
\hline Total & $100.0 \%$ & $100.0 \%$ & $100.0 \%$ & $100.0 \%$ & $100.0 \%$ & $100.0 \%$ & $100.0 \%$ & $100.0 \%$ & $100.0 \%$ \\
\hline
\end{tabular}

lated papers (Liu and Xiao 2004; Cai, Liu, and Xiao 2005), we examine the issue of profit disguising in detail.

\section{Estimated level and ratio of NPD}

Using the method developed in section 2, we report the main NPD statistics for the whole sample as well as for groups classified by ownership, industry, and region. Table 6 shows the amount of NPD as well as the NPD ratio for the whole sample during the 1995-2002 period. There are two sets of NPD statistics in the table: the upper part is derived from imputed profits and the lower part from reported profits. The amount and ratio of NPD are calculated separately for three categories of debts: total liabilities, long-term liabilities, and short-term liabilities. They are similar in size and trend, with the NPD ratio for short-term liabilities declining slightly faster than the ratio for long-term liabilities.

According to imputed profitability, the NPD ratio for the whole sample was stable at around 27-30 percent during 1995-99 but declined rapidly afterward to only 18.4 percent in 2002, with the amount of NPD at about RMB1 trillion.

According to reported profitability, the NPD ratio for the whole sample was 24.1 percent in 1995, rising to 34.3 percent in 1998 and then falling to 22.9 percent in 2002, with the amount of NPDs at about RMB1.3 trillion. According to the CBRC, China's NPL ratio fell sharply to 19.6 percent, with the amount of NPLs at RMB2.5 trillion 
Nonperforming Debts in Chinese Enterprises

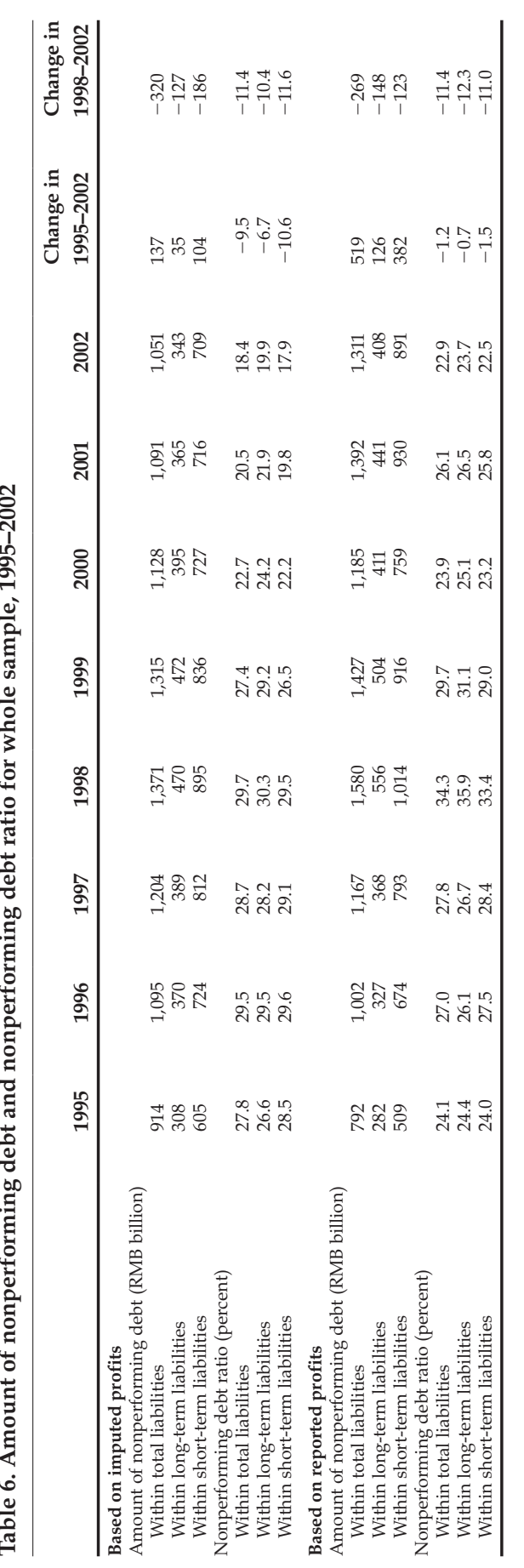

REGULAR

1 LINE LONG 
Table 7. Amount of nonperforming debt and nonperforming debt ratio, estimated from imputed profitability, by ownership, 1995-2002

\begin{tabular}{|c|c|c|c|c|c|c|c|c|}
\hline & 1995 & 1996 & 1997 & 1998 & 1999 & 2000 & 2001 & 2002 \\
\hline \multicolumn{9}{|c|}{$\begin{array}{l}\text { Amount of nonperforming debt estimated } \\
\text { from imputed profitability (RMB billion) }\end{array}$} \\
\hline Private & 0 & 0 & 0 & 2 & 2 & 4 & 5 & 7 \\
\hline Collective & 53 & 55 & 60 & 50 & 47 & 32 & 25 & 22 \\
\hline Mixed & 39 & 63 & 90 & 107 & 165 & 191 & 207 & 178 \\
\hline Foreign & 36 & 69 & 77 & 94 & 74 & 63 & 98 & 94 \\
\hline Hong Kong, Macau, and Taiwan & 26 & 32 & 37 & 68 & 54 & 53 & 53 & 49 \\
\hline State-owned & 761 & 876 & 938 & 1,049 & 972 & 786 & 702 & 701 \\
\hline Total & 915 & 1,095 & 1,202 & 1,370 & 1,314 & 1,129 & 1,090 & 1,051 \\
\hline \multicolumn{9}{|l|}{$\begin{array}{l}\text { Nonperforming ratio estimated from } \\
\text { imputed profitability (percent) }\end{array}$} \\
\hline Private & 0.0 & 0.0 & 0.0 & 18.2 & 11.8 & 12.9 & 8.2 & 7.4 \\
\hline Collective & 23.3 & 20.6 & 21.1 & 17.4 & 16.5 & 12.6 & 11.3 & 10.0 \\
\hline Mixed & 16.9 & 22.5 & 23.7 & 20.8 & 23.9 & 18.5 & 14.5 & 10.8 \\
\hline Foreign & 23.7 & 29.7 & 27.0 & 28.7 & 20.0 & 15.8 & 17.5 & 15.2 \\
\hline Hong Kong, Macau, and Taiwan & 15.9 & 16.8 & 17.3 & 24.6 & 18.2 & 17.4 & 14.8 & 12.6 \\
\hline State-owned & 30.3 & 32.0 & 30.9 & 32.9 & 30.9 & 26.7 & 26.0 & 25.4 \\
\hline Total & 27.8 & 29.5 & 28.6 & 29.7 & 27.4 & 22.7 & 20.5 & 18.4 \\
\hline \multicolumn{9}{|c|}{$\begin{array}{l}\text { Share of nonperforming debt estimated } \\
\text { from imputed profitability (percent) }\end{array}$} \\
\hline Private & 0.0 & 0.0 & 0.0 & 0.1 & 0.2 & 0.4 & 0.5 & 0.7 \\
\hline Collective & 5.8 & 5.0 & 5.0 & 3.6 & 3.6 & 2.8 & 2.3 & 2.1 \\
\hline Mixed & 4.3 & 5.8 & 7.5 & 7.8 & 12.6 & 16.9 & 19.0 & 16.9 \\
\hline Foreign & 3.9 & 6.3 & 6.4 & 6.9 & 5.6 & 5.6 & 9.0 & 8.9 \\
\hline Hong Kong, Macau, and Taiwan & 2.8 & 2.9 & 3.1 & 5.0 & 4.1 & 4.7 & 4.9 & 4.7 \\
\hline State-owned & 83.2 & 80.0 & 78.0 & 76.6 & 74.0 & 69.6 & 64.4 & 66.7 \\
\hline Total & 100.0 & 100.0 & 100.0 & 100.0 & 100.0 & 100.0 & 100.0 & 100.0 \\
\hline
\end{tabular}

by the middle of 2003. Given the different definitions of NPL and NPD, the results for the NPD statistics look consistent with the CBRC statistics for NPLs. In the next section, we will further examine the trend of NPD ratios for the whole sample.

We compare the NPD statistics for different types of enterprises by ownership, where NPD is derived from both imputed profitability (table 7) and reported profitability (table 8). These tables show that NPD ratios vary significantly across types of enterprises by ownership and that SOEs have much higher NPD ratios than NSEs. In 2002, the NPD ratio for SOEs was 25.4 percent by imputed profitability and 25.8 percent by reported profitability. The NPD ratio for private enterprises was 7.4 percent by imputed profitability and 15.8 percent by reported profitability. The NPD ratio for domestic mixed-ownership enterprises was 10.8 percent by imputed profitability and 20.2 percent by reported profitability.

From the NPD statistics in tables 7 and 8, it is possible to decompose the fall of the average NPD ratio for the whole sample into two parts: one resulting from improvement in NPD ratios in each type of enterprise and the other resulting from the redistribution of debts from SOEs to the better-performing NSEs.

1 LINE SHORT

REGULAR

1 LINE LONG 
Table 8. Amount of nonperforming debt and nonperforming debt ratio, estimated from reported profitability, by ownership 1995-2002

\begin{tabular}{|c|c|c|c|c|c|c|c|c|}
\hline & 1995 & 1996 & 1997 & 1998 & 1999 & 2000 & 2001 & 2002 \\
\hline \multicolumn{9}{|c|}{$\begin{array}{l}\text { Amount of nonperforming debt estimated } \\
\text { from reported profitability (RMB billion) }\end{array}$} \\
\hline Private & 0 & 0 & 0 & 4 & 4 & 7 & 12 & 15 \\
\hline Collective & 53 & 67 & 74 & 84 & 69 & 52 & 48 & 42 \\
\hline Mixed & 28 & 37 & 69 & 136 & 172 & 214 & 296 & 332 \\
\hline Foreign & 44 & 82 & 102 & 136 & 107 & 98 & 177 & 139 \\
\hline Hong Kong, Macau, and Taiwan & 29 & 45 & 52 & 89 & 74 & 63 & 77 & 71 \\
\hline State-owned & 638 & 770 & 869 & 1,131 & 999 & 752 & 782 & 712 \\
\hline Total & 792 & 1,001 & 1,166 & 1,580 & 1,425 & 1,186 & 1,392 & 1,311 \\
\hline \multicolumn{9}{|c|}{$\begin{array}{l}\text { Nonperforming debt ratio estimated from } \\
\text { reported profitability (percent) }\end{array}$} \\
\hline Private & 0.0 & 0.0 & 0.0 & 36.4 & 23.5 & 22.6 & 19.4 & 15.8 \\
\hline Collective & 23.3 & 25.0 & 26.1 & 29.3 & 24.3 & 20.5 & 21.7 & 19.2 \\
\hline Mixed & 12.2 & 13.3 & 18.2 & 26.5 & 24.9 & 20.7 & 20.8 & 20.2 \\
\hline Foreign & 28.9 & 35.3 & 35.8 & 41.3 & 28.9 & 24.5 & 31.6 & 22.4 \\
\hline Hong Kong, Macau, and Taiwan & 17.7 & 23.7 & 24.3 & 32.4 & 24.9 & 20.7 & 21.4 & 18.2 \\
\hline State-owned & 25.4 & 28.1 & 28.6 & 35.4 & 31.8 & 25.6 & 28.9 & 25.8 \\
\hline Total & 24.1 & 27.0 & 27.8 & 34.3 & 29.7 & 23.9 & 26.1 & 22.9 \\
\hline \multicolumn{9}{|c|}{$\begin{array}{l}\text { Share of nonperforming debt estimated } \\
\text { from reported profitability (percent) }\end{array}$} \\
\hline Private & 0.0 & 0.0 & 0.0 & 0.3 & 0.3 & 0.6 & 0.9 & 1.1 \\
\hline Collective & 6.7 & 6.7 & 6.3 & 5.3 & 4.8 & 4.4 & 3.4 & 3.2 \\
\hline Mixed & 3.5 & 3.7 & 5.9 & 8.6 & 12.1 & 18.0 & 21.3 & 25.3 \\
\hline Foreign & 5.6 & 8.2 & 8.7 & 8.6 & 7.5 & 8.3 & 12.7 & 10.6 \\
\hline Hong Kong, Macau, and Taiwan & 3.7 & 4.5 & 4.5 & 5.6 & 5.2 & 5.3 & 5.5 & 5.4 \\
\hline State-owned & 80.6 & 76.9 & 74.5 & 71.6 & 70.1 & 63.4 & 56.2 & 54.3 \\
\hline Total & 100.0 & 100.0 & 100.0 & 100.0 & 100.0 & 100.0 & 100.0 & 100.0 \\
\hline
\end{tabular}

Let us assume that $R_{i}^{t}$ is the NPD ratio in year $t$ for enterprise group $i$ and $S_{i}^{t}$ is the share of debts for group $i$ in year $t$. Then the NPD ratio for the whole sample in year $t$ can be calculated from the following formula:

$$
\begin{aligned}
\text { NPD ratio }= & \Sigma_{i} 0.5 *\left(R_{i}^{2002}+R_{i}^{1995}\right) *\left(S_{i}^{2002}-S_{i}^{1995}\right)+ \\
& \Sigma_{i} 0.5 * \Sigma_{i}\left(R_{i}^{2002}-R_{i}^{1995}\right) *\left(S_{i}^{2002}+S_{i}^{1995}\right),
\end{aligned}
$$

where $i=$ private enterprises, collective enterprises, mixed enterprises, foreign enterprises, Hong Kong, Macau, or Taiwanese enterprises (HK-M-Taiwan), or SOEs.

The change in NPD for the whole sample from 1995 to 2002 can be presented equivalently in the following formats:

$$
\begin{aligned}
R^{2002}-R^{1995}= & \Sigma_{i} R_{i}^{2002} * S_{i}^{2002}-\Sigma_{i} R_{i}^{1995} * S_{i}^{1995} \\
& \Sigma_{i} 0.5 *\left(R_{i}^{2002}+R_{i}^{1995}\right) *\left(S_{i}^{2002}-S_{i}^{1995}\right)+ \\
& \Sigma_{i} 0.5 *\left(R_{i}^{2002}-R_{i}^{1995}\right) *\left(S_{i}^{1995}+S_{i}^{2002}\right) .
\end{aligned}
$$

The first term in the above equation is the first component of the change in the NPD ratio for the whole sample during 1995-2002 that can be attributed to the shift of the 
total liabilities across ownership groups while holding the individual ownership group's NPD ratio at its average level for 1995 and 2002. Using statistics from tables 1,7 , and 8 , this first component is -3.86 percent for the imputed-profitability method and -2.33 percent for the reported-profitability method.

The second term in the NPD equation is the component of change in the NPD ratio for the whole sample during 1995-2002 that can be attributed to the fall in individual ownership groups' NPD ratio while holding constant the distribution of total liabilities across ownership groups at its average level for 1995 and 2002. This second component is -4.74 percent for the imputed-profitability method and 1.13 percent for the reported-profitability method.

Hence, according to the imputed-profitability method, the NPD ratio for the whole sample fell from 27.8 percent in 1995 to 18.4 percent in 2002, a drop of 9.4 percentage points. Out of these 9.4 percentage points, 3.86 percentage points can be attributed to the shift of financial resources from SOEs to the better-performing NSEs, which have lower NPD ratios than SOEs.

According to the reported-profitability method, the NPD ratio for the whole sample fell only slightly, from 24.1 percent in 1995 to 22.9 percent in 2002, a drop of only 1.2 percentage points. The decomposing of this 1.2 percentage points shows that the shift of financial resources from SOEs to the better-performing NSEs led to a 2.33percentage-point drop in the NPD ratio for the whole sample, whereas the changes in the NPD ratios for individual ownership groups led to an increase of 1.13 percentage points in the NPD ratio for the whole sample.

Clearly, the decline in the NPD ratio is more significant according to the imputedprofitability method, compared to the reported-profitability method. As previously noted, we are not clear how reported profits are calculated because of large variations in accounting and profit-reporting practices across types of enterprises, but we know exactly how imputed profits are calculated from the financial variables that are used for measuring GDP. We think both measures are useful. The NPD statistics derived from imputed profitability can be used for comparing the underlying performance of different groups of enterprises, and the NPD statistics from reported profitability better reflect the actual outcomes that creditors are going to face when they deal with enterprises.

Tables 9-12 present NPD statistics by industry for 1995-2002. The results shown in tables 9 and 10 are derived using imputed profitability, and the results in tables 11 and 12 are derived from reported profitability. Tables 13-16 present NPD statistics 
Nonperforming Debts in Chinese Enterprises

Table 9. Amount of nonperforming debt by industry, estimated from imputed profitability, 1995-2002, by nonperforming debt in 2002 (RMB billion)

\begin{tabular}{|c|c|c|c|c|c|c|c|c|}
\hline & 1995 & 1996 & 1997 & 1998 & 1999 & 2000 & 2001 & 2002 \\
\hline [44] Electric power & 52 & 86 & 80 & 143 & 188 & 169 & 174 & 177 \\
\hline [26] Raw chemicals & 52 & 65 & 92 & 127 & 108 & 88 & 97 & 89 \\
\hline [06] Coal mining & 63 & 76 & 77 & 81 & 112 & 102 & 67 & 77 \\
\hline [36] Special equipment & 69 & 74 & 86 & 103 & 98 & 93 & 83 & 76 \\
\hline [37] Transport equipment & 63 & 81 & 90 & 101 & 96 & 93 & 103 & 72 \\
\hline [41] Electronic and telecommunications & 47 & 52 & 60 & 64 & 54 & 56 & 52 & 60 \\
\hline [31] Nonmetal products & 42 & 56 & 72 & 65 & 59 & 49 & 48 & 51 \\
\hline [35] Ordinary machinery & 52 & 71 & 74 & 81 & 74 & 65 & 62 & 51 \\
\hline [17] Textile & 113 & 124 & 106 & 105 & 72 & 47 & 44 & 44 \\
\hline [40] Electric equipment & 39 & 51 & 58 & 53 & 52 & 45 & 48 & 40 \\
\hline [22] Papermaking & 13 & 13 & 22 & 28 & 21 & 19 & 25 & 27 \\
\hline [28] Chemical fiber & 17 & 22 & 21 & 33 & 26 & 22 & 24 & 24 \\
\hline [32] Pressing ferrous & 75 & 70 & 85 & 81 & 85 & 62 & 35 & 23 \\
\hline [27] Medical & 13 & 20 & 19 & 20 & 15 & 11 & 13 & 19 \\
\hline [46] Tap water & 7 & 7 & 12 & 9 & 10 & 12 & 13 & 19 \\
\hline [13] Food processing & 32 & 42 & 41 & 42 & 32 & 21 & 17 & 18 \\
\hline [33] Pressing nonferrous & 28 & 35 & 36 & 47 & 28 & 22 & 22 & 16 \\
\hline [42] Instruments & 15 & 17 & 19 & 17 & 14 & 13 & 14 & 16 \\
\hline [14] Food production & 13 & 13 & 16 & 14 & 11 & 8 & 12 & 14 \\
\hline [34] Metal products & 16 & 19 & 23 & 27 & 22 & 18 & 13 & 14 \\
\hline [45] Gas production & 9 & 12 & 11 & 10 & 10 & 13 & 13 & 14 \\
\hline [15] Beverage & 11 & 12 & 13 & 14 & 12 & 13 & 9 & 13 \\
\hline [07] Petroleum extract & 3 & 4 & 13 & 0 & 13 & 11 & 18 & 12 \\
\hline [25] Petroleum processing & 3 & 9 & 7 & 15 & 18 & 8 & 17 & 10 \\
\hline [10] Nonmetal mining & 7 & 5 & 7 & 7 & 6 & 6 & 7 & 9 \\
\hline [29] Rubber & 9 & 9 & 9 & 11 & 18 & 9 & 9 & 9 \\
\hline [30] Plastic & 12 & 12 & 14 & 16 & 14 & 10 & 7 & 9 \\
\hline [09] Nonferrous mining & 5 & 6 & 6 & 9 & 6 & 5 & 6 & 7 \\
\hline [12] Timber logging & 4 & 4 & 6 & 7 & 9 & 8 & 7 & 7 \\
\hline [20] Timber & 5 & 4 & 6 & 8 & 7 & 6 & 5 & 6 \\
\hline [18] Garments & 4 & 5 & 4 & 7 & 5 & 4 & 6 & 5 \\
\hline [23] Printing & 4 & 4 & 6 & 5 & 6 & 6 & 6 & 5 \\
\hline [08] Ferrous mining & 5 & 4 & 1 & 5 & 2 & 2 & 1 & 3 \\
\hline [19] Leather & 6 & 5 & 5 & 7 & 4 & 5 & 3 & 3 \\
\hline [43] Other manufacturing & 3 & 2 & 3 & 3 & 3 & 3 & 3 & 3 \\
\hline [24] Cultural & 1 & 2 & 1 & 3 & 2 & 3 & 2 & 2 \\
\hline [16] Tobacco & 1 & 1 & 1 & 3 & 1 & 2 & 3 & 1 \\
\hline [21] Furniture & 2 & 1 & 1 & 1 & 2 & 2 & 2 & 1 \\
\hline Total & 915 & 1,095 & 1,203 & 1,372 & 1,315 & 1,131 & 1,090 & 1,046 \\
\hline
\end{tabular}

Note: See appendix 2 for full industry names corresponding to industry codes.

by region during 1995-2002. Tables 13 and 14 are derived from imputed profitability, and tables 15 and 16 are derived from reported profitability. Tables 9-16 are sorted by the results in the last column (for 2002) so that readers can easily see the best and worst performers in the quality of enterprise debts by region.

The information here shows the big picture on the quality of enterprise debts across industry and region and can be used by policymakers, as well as by banks, investors, and enterprises as a benchmark against which to check the performance of their own debt portfolios. This information is a public good and contributes to more scientific management of debt risks in China. Bankers from Shanghai and Guangdong might want to know the NPD statistics in their regions. Officials in charge of utilities might want to know how bad that sector's enterprise debts are 
Nonperforming Debts in Chinese Enterprises

Table 10. Nonperforming debt ratios by industry, estimated from imputed profitability, 1995-2002, by nonperforming debt ratio in 2002 (percent)

\begin{tabular}{|c|c|c|c|c|c|c|c|c|}
\hline & 1995 & 1996 & 1997 & 1998 & 1999 & 2000 & 2001 & 2002 \\
\hline [45] Gas production & 90.0 & 92.3 & 84.6 & 58.8 & 58.8 & 68.4 & 72.2 & 60.9 \\
\hline [46] Tap water & 50.0 & 43.8 & 50.0 & 34.6 & 32.3 & 34.3 & 33.3 & 41.3 \\
\hline [36] Special equipment & 46.3 & 46.0 & 48.9 & 55.1 & 52.7 & 48.9 & 45.1 & 39.6 \\
\hline [42] Instruments & 51.7 & 53.1 & 51.4 & 50.0 & 40.0 & 38.2 & 35.0 & 39.0 \\
\hline [06] Coal mining & 49.2 & 51.7 & 45.8 & 44.5 & 54.6 & 48.8 & 30.9 & 35.8 \\
\hline [09] Nonferrous mining & 27.8 & 35.3 & 31.6 & 47.4 & 33.3 & 26.3 & 30.0 & 35.0 \\
\hline [28] Chemical fiber & 27.4 & 31.0 & 28.0 & 39.8 & 28.9 & 26.5 & 32.0 & 32.9 \\
\hline [12] Timber logging & 21.1 & 20.0 & 27.3 & 30.4 & 40.9 & 34.8 & 33.3 & 31.8 \\
\hline [10] Nonmetal mining & 41.2 & 33.3 & 38.9 & 36.8 & 27.3 & 21.4 & 30.4 & 31.0 \\
\hline [08] Ferrous mining & 83.3 & 57.1 & 12.5 & 45.5 & 25.0 & 22.2 & 12.5 & 30.0 \\
\hline [20] Timber & 55.6 & 33.3 & 37.5 & 50.0 & 38.9 & 31.6 & 23.8 & 28.6 \\
\hline [31] Nonmetal products & 30.4 & 33.7 & 38.7 & 33.3 & 29.5 & 25.1 & 23.0 & 23.8 \\
\hline [43] Other manufacturing & 30.0 & 20.0 & 27.3 & 30.0 & 25.0 & 27.3 & 25.0 & 23.1 \\
\hline [35] Ordinary machinery & 33.1 & 39.7 & 38.1 & 39.1 & 36.6 & 31.7 & 29.5 & 23.0 \\
\hline [26] Raw chemicals & 23.0 & 24.6 & 28.3 & 34.8 & 29.3 & 22.7 & 25.5 & 22.3 \\
\hline [22] Papermaking & 24.5 & 20.3 & 30.6 & 38.4 & 26.3 & 21.6 & 20.7 & 21.6 \\
\hline [14] Food production & 35.1 & 31.7 & 38.1 & 29.8 & 22.9 & 16.7 & 21.1 & 21.5 \\
\hline [34] Metal products & 34.8 & 35.8 & 39.0 & 43.5 & 34.9 & 30.5 & 20.0 & 20.6 \\
\hline [24] Cultural & 20.0 & 25.0 & 12.5 & 33.3 & 22.2 & 33.3 & 25.0 & 20.0 \\
\hline [44] Electric power & 17.6 & 27.1 & 22.2 & 27.4 & 30.6 & 23.5 & 21.7 & 19.0 \\
\hline [17] Textile & 44.0 & 45.3 & 36.9 & 38.2 & 29.5 & 20.0 & 19.1 & 18.8 \\
\hline [23] Printing & 28.6 & 25.0 & 31.6 & 25.0 & 26.1 & 26.1 & 22.2 & 18.5 \\
\hline [29] Rubber & 25.0 & 21.4 & 18.8 & 22.0 & 35.3 & 18.4 & 17.3 & 18.0 \\
\hline [40] Electric equipment & 28.5 & 31.1 & 31.4 & 27.2 & 26.8 & 23.1 & 22.0 & 17.7 \\
\hline [21] Furniture & 50.0 & 25.0 & 20.0 & 20.0 & 40.0 & 40.0 & 33.3 & 16.7 \\
\hline [13] Food processing & 36.4 & 39.3 & 36.6 & 36.5 & 30.2 & 20.8 & 16.5 & 16.2 \\
\hline [30] Plastic & 38.7 & 31.6 & 32.6 & 34.8 & 29.2 & 20.4 & 12.7 & 15.0 \\
\hline [37] Transport equipment & 27.5 & 29.3 & 27.7 & 28.1 & 24.9 & 23.3 & 23.4 & 14.7 \\
\hline [27] Medical & 22.0 & 27.4 & 23.5 & 22.2 & 15.5 & 10.5 & 10.7 & 14.3 \\
\hline [41] Electronic and telecommunications & 32.2 & 31.1 & 30.3 & 27.9 & 21.5 & 19.6 & 14.2 & 14.2 \\
\hline [18] Garments & 23.5 & 21.7 & 16.7 & 25.9 & 16.7 & 12.5 & 16.2 & 13.2 \\
\hline [19] Leather & 37.5 & 26.3 & 23.8 & 33.3 & 19.0 & 23.8 & 13.0 & 12.5 \\
\hline [15] Beverage & 15.1 & 14.5 & 13.1 & 13.7 & 11.1 & 11.7 & 8.1 & 11.4 \\
\hline [33] Pressing nonferrous & 29.5 & 34.7 & 30.8 & 35.6 & 20.0 & 15.7 & 14.4 & 9.9 \\
\hline [07] Petroleum extract & 2.0 & 2.5 & 7.9 & 0.0 & 8.1 & 7.0 & 12.1 & 7.8 \\
\hline [25] Petroleum processing & 3.0 & 7.9 & 4.3 & 8.3 & 10.0 & 4.3 & 9.6 & 5.8 \\
\hline [32] Pressing ferrous & 22.7 & 19.7 & 21.5 & 19.5 & 19.3 & 15.2 & 8.4 & 5.2 \\
\hline [16] Tobacco & 1.4 & 1.3 & 1.2 & 4.2 & 1.4 & 2.7 & 2.8 & 0.9 \\
\hline Total & 27.9 & 29.6 & 28.6 & 29.8 & 27.4 & 22.8 & 20.5 & 18.3 \\
\hline
\end{tabular}

Note: See appendix 2 for full industry names corresponding to industry codes.

compared with those of other industries. These patterns of NPD ratios at the aggregate levels by ownership, industry and region are useful for illustrating the overall quality and distribution of enterprise debts in China as well as for contributing to informed policy debates.

\section{Patterns of NPDs}

By applying a simple regression method to the disaggregated NPD ratios, we can summarize the variability in NPD ratios for two relevant dimensions: one is the declining trend in NPD ratios and the other is the gap in NPD ratios across ownership type, industry, and region. Tables 17-19 show the results of six regressions using the group NPD ratios reported in tables 7 and 8, 9 and 11, and 13 and 15, respectively. In 
Nonperforming Debts in Chinese Enterprises

Table 11. Amount of nonperforming debt by industry, estimated from reported profitability, 1995-2002, by nonperforming debt in 2002 (RMB billion)

\begin{tabular}{|c|c|c|c|c|c|c|c|c|}
\hline & 1995 & 1996 & 1997 & 1998 & 1999 & 2000 & 2001 & 2002 \\
\hline [44] Electric power & 83 & 39 & 76 & 119 & 161 & 147 & 173 & 183 \\
\hline [26] Raw chemicals & 39 & 51 & 103 & 174 & 158 & 123 & 134 & 140 \\
\hline [37] Transport equipment & 57 & 68 & 89 & 106 & 114 & 117 & 108 & 117 \\
\hline [25] Petroleum processing & 4 & 22 & 16 & 76 & 39 & 86 & 98 & 76 \\
\hline [41] Electronic and telecommunications & 31 & 41 & 53 & 60 & 54 & 35 & 59 & 73 \\
\hline [31] Nonmetal products & 43 & 64 & 83 & 88 & 74 & 54 & 70 & 72 \\
\hline [17] Textile & 104 & 135 & 128 & 135 & 88 & 51 & 74 & 69 \\
\hline [35] Ordinary machinery & 36 & 52 & 58 & 72 & 64 & 59 & 68 & 65 \\
\hline [36] Special equipment & 50 & 57 & 68 & 88 & 81 & 76 & 86 & 65 \\
\hline [40] Electric equipment & 30 & 41 & 52 & 61 & 52 & 42 & 62 & 45 \\
\hline [28] Chemical fiber & 11 & 20 & 16 & 34 & 27 & 17 & 32 & 32 \\
\hline [33] Pressing nonferrous & 18 & 35 & 35 & 68 & 46 & 21 & 33 & 32 \\
\hline [13] Food processing & 29 & 52 & 53 & 68 & 51 & 28 & 29 & 31 \\
\hline [22] Papermaking & 13 & 17 & 26 & 32 & 27 & 23 & 40 & 30 \\
\hline [15] Beverage & 18 & 21 & 22 & 29 & 27 & 25 & 27 & 29 \\
\hline [32] Pressing ferrous & 45 & 61 & 69 & 68 & 81 & 41 & 43 & 25 \\
\hline [06] Coal mining & 29 & 33 & 31 & 79 & 99 & 78 & 67 & 23 \\
\hline [27] Medical & 12 & 17 & 24 & 23 & 15 & 14 & 17 & 20 \\
\hline [34] Metal products & 15 & 21 & 26 & 30 & 27 & 21 & 19 & 19 \\
\hline [14] Food production & 12 & 15 & 17 & 18 & 13 & 12 & 17 & 18 \\
\hline [30] Plastic & 11 & 12 & 14 & 17 & 14 & 13 & 13 & 15 \\
\hline [46] Tap water & 4 & 5 & 10 & 12 & 9 & 9 & 11 & 15 \\
\hline [16] Tobacco & 5 & 6 & 7 & 6 & 5 & 8 & 25 & 14 \\
\hline [42] Instruments & 10 & 12 & 15 & 17 & 14 & 9 & 11 & 13 \\
\hline [10] Nonmetal mining & 7 & 6 & 6 & 7 & 6 & 7 & 5 & 11 \\
\hline [29] Rubber & 11 & 11 & 10 & 13 & 19 & 18 & 15 & 11 \\
\hline [45] Gas production & 4 & 10 & 9 & 8 & 8 & 10 & 8 & 10 \\
\hline [07] Petroleum extract & 28 & 40 & 6 & 22 & 7 & 2 & 3 & 9 \\
\hline [18] Garments & 3 & 5 & 7 & 8 & 6 & 5 & 9 & 8 \\
\hline [20] Timber & 4 & 5 & 7 & 8 & 7 & 6 & 8 & 8 \\
\hline [19] Leather & 5 & 6 & 6 & 6 & 5 & 5 & 5 & 7 \\
\hline [09] Nonferrous mining & 7 & 8 & 6 & 9 & 6 & 3 & 5 & 6 \\
\hline [12] Timber logging & 3 & 5 & 8 & 7 & 7 & 8 & 7 & 6 \\
\hline [23] Printing & 3 & 3 & 5 & 5 & 4 & 3 & 4 & 4 \\
\hline [08] Ferrous mining & 5 & 3 & 2 & 2 & 3 & 3 & 2 & 3 \\
\hline [43] Other manufacturing & 2 & 3 & 3 & 3 & 4 & 3 & 3 & 3 \\
\hline [21] Furniture & 1 & 1 & 2 & 1 & 1 & 1 & 2 & 1 \\
\hline [24] Cultural & 1 & 1 & 1 & 2 & 1 & 1 & 1 & 1 \\
\hline Total & 793 & 1,004 & 1,169 & 1,581 & 1,424 & 1,184 & 1,393 & 1,309 \\
\hline
\end{tabular}

Note: See appendix 2 for full industry names corresponding to industry codes.

each of the six regressions, the independent variables include a time trend (year) and a categorical variable (ownership, industry, or region). Each categorical variable has the "whole sample" dummy to match the NPD ratio for the whole sample. The regression equations can be written as

$$
\text { NPD ratio }=f(\text { year, categorical variable }) .
$$

We use weighted regressions to discount the impact of the NPD ratios in the early years. (The weights used are listed in the footnotes of tables 17, 18, and 19.) The regression coefficients for the time trend variable (year) indicate how fast the NPD ratio would fall every year based on the variability of the NPD ratios reported for each group in the relevant tables. In principle, the declining trend of NPD ratios for all 
Nonperforming Debts in Chinese Enterprises

Table 12. Nonperforming debt ratios by industry, estimated from reported profitability, 1995-2002, by nonperforming debt ratio in 2002 (percent)

\begin{tabular}{|c|c|c|c|c|c|c|c|c|}
\hline & 1995 & 1996 & 1997 & 1998 & 1999 & 2000 & 2001 & 2002 \\
\hline [25] Petroleum processing & 4.0 & 19.3 & 9.8 & 42.2 & 21.7 & 46.7 & 54.7 & 43.9 \\
\hline [28] Chemical fiber & 17.7 & 28.2 & 21.1 & 41.0 & 29.7 & 20.5 & 42.1 & 43.8 \\
\hline [45] Gas production & 40.0 & 76.9 & 69.2 & 50.0 & 44.4 & 50.0 & 44.4 & 41.7 \\
\hline [10] Nonmetal mining & 43.8 & 37.5 & 33.3 & 35.0 & 27.3 & 25.9 & 21.7 & 37.9 \\
\hline [20] Timber & 40.0 & 41.7 & 43.8 & 50.0 & 41.2 & 31.6 & 38.1 & 36.4 \\
\hline [26] Raw chemicals & 17.3 & 19.3 & 31.6 & 47.7 & 42.8 & 31.7 & 35.3 & 34.9 \\
\hline [36] Special equipment & 33.8 & 35.6 & 38.6 & 47.1 & 43.5 & 39.8 & 46.7 & 33.9 \\
\hline [31] Nonmetal products & 31.2 & 38.3 & 44.9 & 45.4 & 37.0 & 27.7 & 33.5 & 33.6 \\
\hline [46] Tap water & 26.7 & 31.3 & 43.5 & 44.4 & 29.0 & 26.5 & 28.2 & 32.6 \\
\hline [42] Instruments & 34.5 & 37.5 & 40.5 & 51.5 & 40.0 & 26.5 & 27.5 & 31.7 \\
\hline [08] Ferrous mining & 71.4 & 37.5 & 25.0 & 18.2 & 33.3 & 37.5 & 25.0 & 30.0 \\
\hline [17] Textile & 40.3 & 49.3 & 44.6 & 49.1 & 35.9 & 21.8 & 32.0 & 29.5 \\
\hline [35] Ordinary machinery & 22.8 & 28.9 & 29.9 & 34.8 & 31.7 & 28.8 & 32.5 & 29.4 \\
\hline [19] Leather & 31.3 & 31.6 & 28.6 & 28.6 & 23.8 & 22.7 & 21.7 & 29.2 \\
\hline [09] Nonferrous mining & 38.9 & 47.1 & 31.6 & 47.4 & 33.3 & 15.8 & 25.0 & 28.6 \\
\hline [34] Metal products & 31.9 & 38.9 & 44.1 & 48.4 & 42.9 & 35.6 & 29.2 & 28.4 \\
\hline [13] Food processing & 33.3 & 48.6 & 47.7 & 59.1 & 48.1 & 28.0 & 28.2 & 27.9 \\
\hline [14] Food production & 32.4 & 36.6 & 40.5 & 39.1 & 27.1 & 24.5 & 30.4 & 27.7 \\
\hline [12] Timber logging & 15.8 & 25.0 & 36.4 & 30.4 & 31.8 & 34.8 & 31.8 & 26.1 \\
\hline [15] Beverage & 24.7 & 25.3 & 22.2 & 28.4 & 25.2 & 22.5 & 24.5 & 25.4 \\
\hline [30] Plastic & 35.5 & 31.6 & 32.6 & 37.0 & 29.2 & 26.5 & 23.6 & 24.6 \\
\hline [22] Papermaking & 24.5 & 26.2 & 36.1 & 43.8 & 33.8 & 26.4 & 33.1 & 24.0 \\
\hline [37] Transport equipment & 24.9 & 24.6 & 27.4 & 29.4 & 29.6 & 29.2 & 24.5 & 23.8 \\
\hline [29] Rubber & 30.6 & 25.6 & 20.8 & 25.5 & 37.3 & 36.7 & 28.8 & 21.6 \\
\hline [43] Other manufacturing & 22.2 & 27.3 & 27.3 & 33.3 & 33.3 & 27.3 & 23.1 & 21.4 \\
\hline [18] Garments & 17.6 & 21.7 & 29.2 & 29.6 & 20.7 & 15.2 & 23.7 & 20.5 \\
\hline [40] Electric equipment & 22.1 & 25.0 & 28.1 & 31.3 & 26.8 & 21.5 & 28.4 & 19.9 \\
\hline [33] Pressing nonferrous & 18.9 & 34.7 & 30.2 & 51.5 & 32.9 & 15.1 & 21.4 & 19.8 \\
\hline [44] Electric power & 28.0 & 12.3 & 21.1 & 22.8 & 26.2 & 20.5 & 21.6 & 19.6 \\
\hline [41] Electronic and telecommunications & 21.4 & 24.6 & 26.6 & 26.2 & 21.5 & 12.2 & 16.1 & 17.2 \\
\hline [21] Furniture & 25.0 & 33.3 & 40.0 & 20.0 & 20.0 & 20.0 & 33.3 & 16.7 \\
\hline [27] Medical & 20.3 & 23.6 & 29.3 & 25.3 & 15.5 & 13.3 & 14.0 & 15.0 \\
\hline [23] Printing & 21.4 & 17.6 & 25.0 & 23.8 & 18.2 & 13.0 & 14.8 & 14.8 \\
\hline [16] Tobacco & 7.0 & 7.9 & 8.5 & 8.3 & 7.0 & 10.8 & 22.9 & 13.0 \\
\hline [24] Cultural & 16.7 & 12.5 & 12.5 & 22.2 & 11.1 & 11.1 & 12.5 & 11.1 \\
\hline [06] Coal mining & 22.5 & 22.3 & 18.5 & 43.4 & 48.1 & 37.3 & 30.9 & 10.7 \\
\hline [07] Petroleum extract & 18.5 & 25.5 & 3.7 & 12.9 & 4.4 & 1.3 & 2.0 & 5.9 \\
\hline [32] Pressing ferrous & 13.6 & 17.1 & 17.5 & 16.3 & 18.4 & 10.1 & 10.3 & 5.6 \\
\hline Total & 24.1 & 27.1 & 27.8 & 34.3 & 29.6 & 23.9 & 26.1 & 22.9 \\
\hline
\end{tabular}

Note: See appendix 2 for full industry names corresponding to industry codes.

the groups is related to the improvement of the general market environment of the Chinese economy as a result of reform and opening. The regression coefficients for the categorical variable indicate the average gap between the NPD ratio of that particular category and the NPD ratio of the base category (which is indicated by a zero value for the coefficient and a blank value for the t-statistics in the tables) after removing the influence of the declining trend in NPD ratio. The negative sign means "lower than" the NPD ratio of the base category.

For example, table 17 shows that based on the NPD ratios estimated from imputed profitability (reported in table 7), the NPD ratio for a particular group is likely to decline on average by 1.5 percentage points each year. For private enterprises, NPD ratios in a given year are likely to be 21.3 percentage points lower than those for SOEs 
Table 13. Amount of nonperforming debt by region, estimated from imputed profitability, 1995-2002, by nonperforming debt in 2002 (RMB billion)

\begin{tabular}{lrrrrrrrr}
\hline & $\mathbf{1 9 9 5}$ & $\mathbf{1 9 9 6}$ & $\mathbf{1 9 9 7}$ & $\mathbf{1 9 9 8}$ & $\mathbf{1 9 9 9}$ & $\mathbf{2 0 0 0}$ & $\mathbf{2 0 0 1}$ & $\mathbf{2 0 0 2}$ \\
\hline [31] Shanghai & 70 & 94 & 95 & 98 & 92 & 78 & 69 & 81 \\
[44] Guangdong & 64 & 90 & 113 & 131 & 106 & 90 & 86 & 80 \\
[41] Henan & 23 & 39 & 37 & 63 & 61 & 64 & 69 & 72 \\
[23] Heilongiiang & 60 & 58 & 56 & 69 & 71 & 62 & 56 & 58 \\
[21] Liaoning & 105 & 117 & 115 & 110 & 87 & 63 & 75 & 57 \\
[50] Sichuan + Chongqing & 71 & 71 & 109 & 88 & 127 & 124 & 104 & 57 \\
[12] Tianjin & 52 & 32 & 38 & 61 & 53 & 24 & 39 & 56 \\
[42] Hubei & 27 & 53 & 39 & 36 & 34 & 36 & 35 & 46 \\
[13] Hebei & 33 & 45 & 41 & 42 & 47 & 45 & 49 & 45 \\
[37] Shandong & 47 & 48 & 50 & 64 & 69 & 58 & 44 & 45 \\
[11] Beijing & 27 & 45 & 67 & 99 & 68 & 64 & 55 & 42 \\
[22] Jilin & 36 & 35 & 38 & 39 & 35 & 32 & 39 & 41 \\
[32] Jiangsu & 39 & 49 & 57 & 57 & 59 & 51 & 49 & 40 \\
[61] Shaanxi & 37 & 49 & 49 & 46 & 48 & 38 & 46 & 38 \\
[14] Shanxi & 24 & 33 & 29 & 50 & 44 & 33 & 24 & 35 \\
[54] Tibet + Qinghai + Ningxia & 12 & 18 & 23 & 18 & 14 & 11 & 11 & 34 \\
[43] Hunan & 29 & 28 & 33 & 37 & 35 & 34 & 30 & 32 \\
[52] Guizhou & 16 & 15 & 15 & 28 & 25 & 28 & 26 & 31 \\
[34] Anhui & 26 & 27 & 26 & 35 & 31 & 44 & 14 & 23 \\
[45] Guangxi & 18 & 18 & 23 & 20 & 21 & 17 & 16 & 22 \\
[15] Inner Mongolia & 17 & 16 & 14 & 27 & 46 & 25 & 34 & 21 \\
[53] Yunnan & 9 & 11 & 20 & 24 & 23 & 17 & 20 & 21 \\
[35] Fujian & 7 & 10 & 11 & 11 & 6 & 8 & 34 & 20 \\
[62] Gansu & 12 & 22 & 29 & 30 & 28 & 26 & 15 & 15 \\
[36] Jiangxi & 20 & 26 & 29 & 30 & 32 & 19 & 18 & 12 \\
[33] Zhejiang & 19 & 25 & 24 & 37 & 25 & 18 & 17 & 11 \\
[65] Xinjiang & 9 & 13 & 14 & 16 & 21 & 17 & 15 & 11 \\
[46] Hainan & 4 & 7 & 9 & 5 & 8 & 2 & 4 & 3 \\
Total & 913 & 1,094 & 1,203 & 1,371 & 1,316 & 1,128 & 1,093 & 1,049 \\
\hline
\end{tabular}

Table 14. Nonperforming debt ratios by region, estimated from imputed profitability, 19952002, by nonperforming debt ratio in 2002 (percent)

\begin{tabular}{|c|c|c|c|c|c|c|c|c|}
\hline & 1995 & 1996 & 1997 & 1998 & 1999 & 2000 & 2001 & 2002 \\
\hline [54] Tibet + Qinghai + Ningxia & 35.3 & 52.9 & 53.5 & 31.6 & 24.6 & 17.7 & 20.0 & 42.5 \\
\hline [52] Guizhou & 36.4 & 37.5 & 31.9 & 47.5 & 39.7 & 37.8 & 36.1 & 40.3 \\
\hline [12] Tianjin & 48.1 & 29.4 & 32.2 & 39.1 & 34.2 & 16.6 & 25.5 & 32.0 \\
\hline [23] Heilongjiang & 40.0 & 38.9 & 33.7 & 36.3 & 38.8 & 32.6 & 29.5 & 29.7 \\
\hline [41] Henan & 17.3 & 25.0 & 22.3 & 30.9 & 29.0 & 29.2 & 29.5 & 28.3 \\
\hline [14] Shanxi & 30.4 & 37.1 & 29.0 & 38.5 & 34.1 & 24.4 & 19.0 & 26.5 \\
\hline [11] Beijing & 27.6 & 39.8 & 51.1 & 59.6 & 44.2 & 40.8 & 29.6 & 24.9 \\
\hline [45] Guangxi & 30.5 & 29.5 & 32.9 & 24.7 & 24.7 & 18.9 & 18.0 & 24.4 \\
\hline [61] Shaanxi & 47.4 & 55.7 & 50.0 & 45.1 & 35.8 & 28.6 & 32.4 & 24.2 \\
\hline [15] Inner Mongolia & 33.3 & 28.6 & 22.2 & 38.6 & 59.0 & 34.7 & 41.0 & 24.1 \\
\hline [22] Jilin & 31.3 & 25.5 & 24.8 & 25.2 & 22.0 & 18.8 & 23.9 & 23.7 \\
\hline [31] Shanghai & 30.3 & 34.3 & 29.4 & 29.1 & 26.5 & 23.4 & 19.8 & 21.6 \\
\hline [43] Hunan & 36.7 & 32.6 & 33.3 & 33.0 & 29.4 & 27.4 & 21.3 & 21.5 \\
\hline [46] Hainan & 33.3 & 43.8 & 50.0 & 25.0 & 34.8 & 10.5 & 25.0 & 18.8 \\
\hline [53] Yunnan & 15.5 & 17.5 & 29.4 & 32.4 & 30.3 & 22.7 & 19.2 & 18.4 \\
\hline [42] Hubei & 20.0 & 32.3 & 21.4 & 16.7 & 15.5 & 15.5 & 15.3 & 18.2 \\
\hline [13] Hebei & 23.1 & 27.1 & 22.2 & 21.1 & 22.1 & 20.0 & 19.7 & 17.6 \\
\hline [50] Sichuan + Chongqing & 38.8 & 35.7 & 46.8 & 36.7 & 39.8 & 42.0 & 34.3 & 17.5 \\
\hline [21] Liaoning & 35.8 & 37.7 & 33.3 & 30.5 & 27.2 & 19.5 & 22.3 & 16.1 \\
\hline [34] Anhui & 32.1 & 29.7 & 24.1 & 32.4 & 27.4 & 33.8 & 10.9 & 16.0 \\
\hline [62] Gansu & 22.2 & 37.3 & 37.2 & 32.6 & 33.3 & 31.0 & 16.9 & 16.0 \\
\hline [44] Guangdong & 21.4 & 25.9 & 27.3 & 30.0 & 24.4 & 19.3 & 16.9 & 14.3 \\
\hline [65] Xinjiang & 15.8 & 19.1 & 18.9 & 20.3 & 26.3 & 21.3 & 18.5 & 13.9 \\
\hline [36] Jiangxi & 34.5 & 38.2 & 40.3 & 38.5 & 36.8 & 21.3 & 20.0 & 13.6 \\
\hline [35] Fujian & 14.9 & 18.2 & 20.0 & 20.0 & 9.7 & 12.1 & 25.2 & 13.3 \\
\hline [37] Shandong & 17.9 & 16.3 & 14.8 & 18.1 & 16.6 & 13.3 & 9.7 & 9.2 \\
\hline [32] Jiangsu & 17.3 & 18.2 & 19.1 & 17.8 & 18.0 & 13.8 & 10.7 & 8.0 \\
\hline [33] Zhejiang & 15.8 & 17.5 & 15.7 & 23.6 & 15.6 & 10.8 & 10.0 & 5.9 \\
\hline Total & 27.8 & 29.5 & 28.7 & 29.8 & 27.4 & 22.7 & 20.5 & 18.3 \\
\hline
\end{tabular}

REGULAR

1 LINE LONG 
Table 15. Amount of nonperforming debt by region, estimated from reported profitability, 1995-2002, by nonperforming debt in 2002 (RMB billion)

\begin{tabular}{|c|c|c|c|c|c|c|c|c|}
\hline & 1995 & 1996 & 1997 & 1998 & 1999 & 2000 & 2001 & 2002 \\
\hline [21] Liaoning & 89 & 87 & 95 & 117 & 77 & 46 & 94 & 114 \\
\hline [44] Guangdong & 68 & 121 & 137 & 170 & 151 & 118 & 131 & 111 \\
\hline [50] Sichuan + Chongqing & 61 & 60 & 71 & 94 & 129 & 101 & 91 & 88 \\
\hline [32] Jiangsu & 41 & 54 & 63 & 83 & 74 & 64 & 96 & 73 \\
\hline [31] Shanghai & 34 & 50 & 63 & 82 & 72 & 47 & 63 & 69 \\
\hline [12] Tianjin & 28 & 33 & 41 & 66 & 55 & 57 & 55 & 67 \\
\hline [37] Shandong & 46 & 45 & 51 & 68 & 67 & 56 & 72 & 63 \\
\hline [22] Jilin & 35 & 42 & 64 & 78 & 57 & 46 & 52 & 62 \\
\hline [42] Hubei & 33 & 54 & 60 & 77 & 73 & 79 & 65 & 62 \\
\hline [23] Heilongjiang & 47 & 59 & 58 & 104 & 69 & 74 & 74 & 56 \\
\hline [43] Hunan & 24 & 31 & 45 & 54 & 37 & 48 & 41 & 55 \\
\hline [13] Hebei & 28 & 30 & 40 & 54 & 47 & 48 & 64 & 53 \\
\hline [61] Shaanxi & 31 & 34 & 38 & 49 & 53 & 46 & 48 & 45 \\
\hline [41] Henan & 34 & 44 & 45 & 51 & 51 & 55 & 69 & 43 \\
\hline [62] Gansu & 16 & 16 & 17 & 41 & 36 & 11 & 31 & 40 \\
\hline [35] Fujian & 9 & 10 & 8 & 11 & 9 & 10 & 38 & 36 \\
\hline [36] Jiangxi & 19 & 24 & 26 & 35 & 36 & 32 & 32 & 31 \\
\hline [54] Tibet + Qinghai + Ningxia & 14 & 17 & 21 & 26 & 21 & 25 & 10 & 30 \\
\hline [45] Guangxi & 14 & 27 & 31 & 35 & 30 & 23 & 25 & 29 \\
\hline [14] Shanxi & 15 & 20 & 24 & 54 & 53 & 38 & 35 & 28 \\
\hline [15] Inner Mongolia & 18 & 16 & 16 & 30 & 36 & 24 & 30 & 28 \\
\hline [34] Anhui & 21 & 22 & 25 & 52 & 49 & 25 & 33 & 26 \\
\hline [53] Yunnan & 8 & 9 & 15 & 21 & 25 & 19 & 24 & 26 \\
\hline [65] Xinjiang & 10 & 36 & 16 & 21 & 25 & 22 & 28 & 26 \\
\hline [11] Beijing & 11 & 18 & 37 & 40 & 39 & 37 & 51 & 22 \\
\hline [33] Zhejiang & 19 & 22 & 28 & 38 & 26 & 20 & 23 & 14 \\
\hline [52] Guizhou & 15 & 13 & 20 & 18 & 16 & 11 & 11 & 11 \\
\hline [46] Hainan & 4 & 8 & 11 & 8 & 12 & 4 & 6 & 4 \\
\hline Total & 792 & 1,002 & 1,166 & 1,577 & 1,425 & 1,186 & 1,392 & 1,312 \\
\hline
\end{tabular}

Table 16. Nonperforming debt ratios by region, estimated from reported profitability, 19952002, by nonperforming debt ratio in 2002 (percent)

\begin{tabular}{|c|c|c|c|c|c|c|c|c|}
\hline & 1995 & 1996 & 1997 & 1998 & 1999 & 2000 & 2001 & 2002 \\
\hline [62] Gansu & 29.1 & 27.1 & 21.5 & 44.6 & 42.9 & 13.1 & 35.2 & 43.0 \\
\hline [12] Tianjin & 25.9 & 30.0 & 34.5 & 42.6 & 35.5 & 39.6 & 35.9 & 38.5 \\
\hline [54] Tibet + Qinghai + Ningxia & 41.2 & 50.0 & 48.8 & 45.6 & 36.8 & 39.7 & 18.2 & 38.0 \\
\hline [43] Hunan & 30.8 & 36.0 & 45.5 & 48.6 & 31.1 & 38.7 & 29.1 & 37.2 \\
\hline [22] Jilin & 30.2 & 30.7 & 41.8 & 50.3 & 35.8 & 27.1 & 31.9 & 35.8 \\
\hline [36] Jiangxi & 32.8 & 35.3 & 36.1 & 44.3 & 41.4 & 36.0 & 35.6 & 35.2 \\
\hline [65] Xinjiang & 17.5 & 52.2 & 21.3 & 26.9 & 31.6 & 27.5 & 35.0 & 32.9 \\
\hline [45] Guangxi & 23.7 & 43.5 & 44.3 & 43.2 & 35.3 & 25.3 & 27.8 & 32.2 \\
\hline [21] Liaoning & 30.4 & 28.0 & 27.5 & 32.3 & 24.1 & 14.3 & 28.1 & 32.2 \\
\hline [15] Inner Mongolia & 34.6 & 28.6 & 25.4 & 42.9 & 45.6 & 32.9 & 36.1 & 31.8 \\
\hline [61] Shaanxi & 39.7 & 38.6 & 38.4 & 48.5 & 39.6 & 34.6 & 33.8 & 28.8 \\
\hline [23] Heilongjiang & 31.3 & 39.6 & 34.9 & 54.7 & 37.7 & 38.7 & 38.9 & 28.6 \\
\hline [50] Sichuan + Chongqing & 33.3 & 30.2 & 30.5 & 39.0 & 40.4 & 34.2 & 30.0 & 27.1 \\
\hline [46] Hainan & 36.4 & 53.3 & 61.1 & 40.0 & 50.0 & 20.0 & 37.5 & 25.0 \\
\hline [42] Hubei & 24.4 & 32.9 & 33.0 & 35.5 & 33.5 & 34.1 & 28.5 & 24.5 \\
\hline [35] Fujian & 19.1 & 18.2 & 14.8 & 20.4 & 14.5 & 15.2 & 28.1 & 24.0 \\
\hline [53] Yunnan & 13.8 & 14.1 & 22.1 & 28.0 & 33.3 & 25.3 & 23.3 & 22.8 \\
\hline [14] Shanxi & 19.0 & 22.7 & 24.0 & 41.9 & 41.4 & 27.9 & 27.8 & 21.2 \\
\hline [13] Hebei & 19.6 & 18.1 & 21.7 & 27.1 & 22.1 & 21.4 & 25.8 & 20.6 \\
\hline [44] Guangdong & 22.8 & 34.8 & 33.1 & 39.0 & 34.8 & 25.2 & 25.7 & 19.9 \\
\hline [31] Shanghai & 14.7 & 18.2 & 19.5 & 24.4 & 20.7 & 14.1 & 18.1 & 18.4 \\
\hline [34] Anhui & 25.9 & 24.2 & 23.1 & 48.1 & 43.0 & 19.2 & 25.8 & 17.9 \\
\hline [41] Henan & 25.6 & 28.0 & 27.3 & 25.1 & 24.3 & 25.1 & 29.5 & 16.9 \\
\hline [32] Jiangsu & 18.1 & 20.1 & 21.1 & 25.9 & 22.6 & 17.3 & 21.1 & 14.5 \\
\hline [52] Guizhou & 34.1 & 32.5 & 41.7 & 30.5 & 25.0 & 14.9 & 15.3 & 14.3 \\
\hline [11] Beijing & 11.2 & 16.1 & 28.2 & 24.1 & 25.3 & 23.4 & 27.3 & 13.0 \\
\hline [37] Shandong & 17.6 & 15.3 & 15.2 & 19.2 & 16.1 & 12.8 & 15.8 & 12.9 \\
\hline [33] Zhejiang & 15.7 & 15.4 & 18.3 & 24.2 & 16.4 & 12.0 & 13.5 & 7.5 \\
\hline Total & 24.1 & 27.0 & 27.8 & 34.2 & 29.7 & 23.9 & 26.1 & 22.9 \\
\hline
\end{tabular}


Nonperforming Debts in Chinese Enterprises

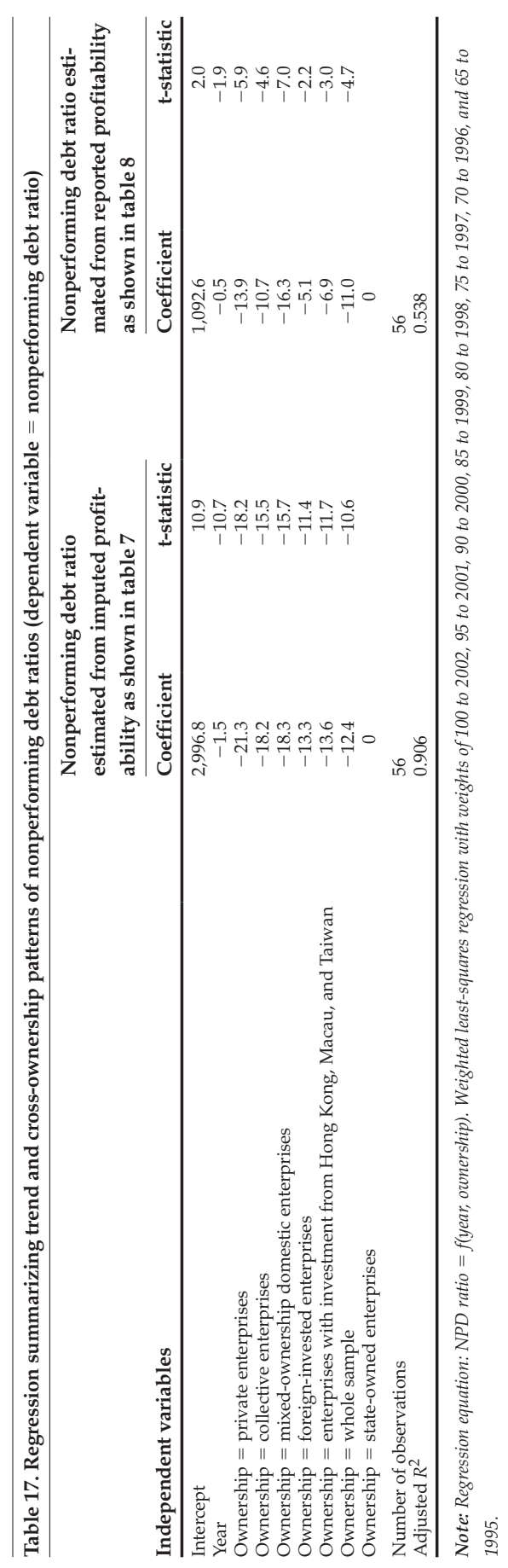

REGULAR

1 LINE LONG 
Table 18. Regression summarizing trend and cross-industry patterns of nonperforming debt ratios (dependent variable $=$ nonperforming debt ratio)

\begin{tabular}{|c|c|c|c|c|}
\hline \multirow[b]{2}{*}{ Independent variables } & \multicolumn{2}{|c|}{$\begin{array}{l}\text { Nonperforming debt ratio } \\
\text { based on imputed profit- } \\
\text { ability as shown in table } 9\end{array}$} & \multicolumn{2}{|c|}{$\begin{array}{l}\text { Nonperforming debt ratio } \\
\text { based on reported profit- } \\
\text { ability as shown in table } 11\end{array}$} \\
\hline & Coefficient & t-statistic & Coefficient & t-statistic \\
\hline Intercept & $3,571.4$ & 15.7 & $1,754.7$ & 6.4 \\
\hline Year 1 & -1.8 & -15.6 & -0.9 & -6.3 \\
\hline [07] Petroleum extract & -25.3 & -11.1 & -17.3 & -6.3 \\
\hline [44] Electric power & -13.9 & -6.1 & -13.1 & -4.8 \\
\hline [16] Tobacco & -26.6 & -11.7 & -13.0 & -4.7 \\
\hline [24] Cultural & -7.1 & -3.1 & -8.5 & -3.1 \\
\hline [27] Medical & -15.6 & -6.9 & -7.8 & -2.9 \\
\hline [23] Printing & -1.2 & -0.5 & -7.5 & -2.7 \\
\hline [18] Garments & -9.5 & -4.2 & -5.3 & -1.9 \\
\hline [21] Furniture & -7.3 & -3.2 & -4.6 & -1.7 \\
\hline [43] Other manufacturing & -8.2 & -3.6 & -4.0 & -1.5 \\
\hline Industry $=$ whole sample & -8.4 & -3.7 & -4.0 & -1.5 \\
\hline [26] Raw chemicals & -8.4 & -3.7 & -3.0 & -1.1 \\
\hline [10] Nonmetal mining & -3.2 & -1.4 & -2.1 & -0.8 \\
\hline [15] Beverage & -18.0 & -7.9 & -1.4 & -0.5 \\
\hline [40] Electric equipment & -5.4 & -2.4 & -1.0 & -0.4 \\
\hline [41] Electronic and telecommunications & 1.0 & 0.4 & -0.6 & -0.2 \\
\hline [25] Petroleum processing & -15.5 & -6.8 & -0.5 & -0.2 \\
\hline [22] Papermaking & -11.3 & -5.0 & -0.1 & 0.0 \\
\hline [46] Tap water & 0.0 & & 0.0 & \\
\hline [19] Leather & -5.9 & -2.6 & 0.0 & 0.0 \\
\hline [06] Coal mining & 8.6 & 3.8 & 0.2 & 0.1 \\
\hline [33] Pressing nonferrous & -6.9 & -3.0 & 0.6 & 0.2 \\
\hline [09] Nonferrous mining & 7.3 & 3.2 & 0.7 & 0.3 \\
\hline [08] Ferrous mining & -1.3 & -0.6 & 1.4 & 0.5 \\
\hline [29] Rubber & -7.2 & -3.2 & 1.8 & 0.6 \\
\hline [37] Transport equipment & -0.3 & -0.1 & 2.1 & 0.8 \\
\hline [35] Ordinary machinery & 1.0 & 0.4 & 3.3 & 1.2 \\
\hline [30] Plastic & -4.9 & -2.1 & 3.8 & 1.4 \\
\hline [34] Metal products & -1.2 & -0.5 & 4.2 & 1.5 \\
\hline [32] Pressing ferrous & -4.9 & -2.1 & 4.4 & 1.6 \\
\hline [31] Nonmetal products & -6.8 & -3.0 & 4.6 & 1.7 \\
\hline [28] Chemical fiber & -3.5 & -1.5 & 4.6 & 1.7 \\
\hline [12] Timber logging & 4.7 & 2.1 & 4.6 & 1.7 \\
\hline [14] Food production & -4.8 & -2.1 & 5.1 & 1.8 \\
\hline [17] Textile & -5.0 & -2.2 & 5.4 & 2.0 \\
\hline [42] Instruments & 9.5 & 4.2 & 5.5 & 2.0 \\
\hline [36] Special equipment & 6.9 & 3.0 & 6.9 & 2.5 \\
\hline [13] Food processing & -4.9 & -2.2 & 8.7 & 3.1 \\
\hline [20] Timber & 2.6 & 1.1 & 8.7 & 3.2 \\
\hline [45] Gas production & 35.0 & 15.4 & 22.1 & 8.0 \\
\hline Number of observations & 312 & & 312 & \\
\hline Adjusted $R^{2}$ & 0.850 & & 0.610 & \\
\hline
\end{tabular}

Note: Regression equation: NPD ratio $=f(y e a r$, industry). Weighted least-squares regression with weights of 100 to 2002, 95 to 2001, 90 to 2000, 85 to 1999, 80 to 1998, 75 to 1997, 70 to 1996, and 65 to 1995. See appendix 2 for full industry names corresponding to industry codes.

in that year. The NPD ratio for the whole sample for a given year is likely to be 12.4 percent lower than the NPD ratio for SOEs in that year.

The regression results shown in tables 17-19 can be used to make rough predictions about NPD ratios for a particular group in the future. But these rough predictions are based only on the pattern of NPD ratios during 1995-2002. Figures 1 and 2 show 
Table 19. Regression summarizing trend and cross-region patterns of nonperforming debt ratios (dependent variable $=$ nonperforming debt ratio)

\begin{tabular}{|c|c|c|c|c|}
\hline \multirow[b]{2}{*}{ Independent variables } & \multicolumn{2}{|c|}{$\begin{array}{l}\text { Nonperforming debt ratio } \\
\text { based on imputed profitabil- } \\
\text { ity as shown in } \\
\text { table } 13\end{array}$} & \multicolumn{2}{|c|}{$\begin{array}{l}\text { Nonperforming debt ratio } \\
\text { based on reported profitabil- } \\
\text { ity as shown in } \\
\text { table } 15 \\
\end{array}$} \\
\hline & Coefficient & t-statistic & Coefficient & t-statistic \\
\hline $\begin{array}{l}\text { Intercept } \\
\text { Year } \\
\text { [37] Shandong } \\
\text { [33] Zhejiang } \\
\text { [35] Fujian } \\
\text { [32] Jiangsu } \\
\text { [11] Beijing } \\
\text { [31] Shanghai } \\
\text { Region = whole sample } \\
\text { [13] Hebei } \\
\text { [15] Inner Mongolia } \\
\text { [41] Henan } \\
\text { [14] Shanxi } \\
\text { [53] Yunnan } \\
\text { [34] Anhui } \\
\text { [44] Guangdong } \\
\text { [50] Sichuan + Chongqing } \\
\text { [42] Hubei } \\
\text { [21] Liaoning } \\
\text { [12] Tianjin } \\
\text { [54] Tibet + Qinghai + Ningxia } \\
\text { [22] Jilin } \\
\text { [23] Heilongiang } \\
\text { [45] Guangxi } \\
\text { [36] Jiangxi } \\
\text { [46] Hainan } \\
\text { [62] Gansu } \\
\text { [52] Guizhou } \\
\text { [43] Hunan } \\
\text { [61] Shaanxi } \\
\text { [65] Xinjiang }\end{array}$ & $\begin{array}{r}4,537.3 \\
-2.2 \\
-24.9 \\
-24.1 \\
-18.5 \\
-24.0 \\
5.4 \\
-10.8 \\
-17.6 \\
-15.7 \\
-16.5 \\
-17.6 \\
-7.8 \\
-6.0 \\
-19.1 \\
-13.2 \\
-7.3 \\
-14.8 \\
-4.3 \\
-4.0 \\
-4.5 \\
-4.3 \\
-4.9 \\
-14.0 \\
-8.1 \\
-7.7 \\
-3.4 \\
2.4 \\
-3.7 \\
1.4 \\
0.0\end{array}$ & $\begin{array}{r}16.1 \\
-16.0 \\
-10.2 \\
-9.9 \\
-7.6 \\
-9.9 \\
2.2 \\
-4.4 \\
-7.2 \\
-6.5 \\
-6.8 \\
-7.2 \\
-3.2 \\
-2.5 \\
-7.8 \\
-5.4 \\
-3.0 \\
-6.1 \\
-1.8 \\
-1.7 \\
-1.9 \\
-1.8 \\
-2.0 \\
-5.8 \\
-3.3 \\
-3.2 \\
-1.4 \\
1.0 \\
-1.5 \\
0.6\end{array}$ & $\begin{array}{r}2,022.1 \\
-1.0 \\
-28.2 \\
-25.1 \\
-22.3 \\
-21.1 \\
-20.6 \\
-19.3 \\
-19.3 \\
-18.8 \\
-14.4 \\
-14.0 \\
-12.5 \\
-10.4 \\
-9.5 \\
-9.3 \\
-9.1 \\
-7.2 \\
-6.1 \\
-5.0 \\
-4.9 \\
-4.0 \\
-3.5 \\
-3.3 \\
-2.7 \\
-2.1 \\
-2.1 \\
-1.5 \\
-1.0 \\
-0.6 \\
0.0\end{array}$ & $\begin{array}{r}5.5 \\
-5.4 \\
-8.9 \\
-8.0 \\
-7.0 \\
-6.7 \\
-6.5 \\
-6.1 \\
-6.1 \\
-5.9 \\
-4.6 \\
-4.4 \\
-3.9 \\
-3.3 \\
-3.0 \\
-2.9 \\
-2.9 \\
-2.3 \\
-1.9 \\
-1.6 \\
-1.6 \\
-1.3 \\
-1.1 \\
-1.0 \\
-0.8 \\
-0.7 \\
-0.7 \\
-0.5 \\
-0.3 \\
-0.2 \\
\end{array}$ \\
\hline $\begin{array}{l}\text { Number of observations } \\
\text { Adjusted } R^{2}\end{array}$ & $\begin{array}{l}232 \\
0.790\end{array}$ & & $\begin{array}{l}232 \\
0.629\end{array}$ & \\
\hline
\end{tabular}

Note: Regression equation: NPD ratio $=f($ year, region). Weighted least-squares regression with weights of 100 to 2002, 95 to 2001, 90 to 2000, 85 to 1999, 80 to 1998, 75 to 1997, 70 to 1996, and 65 to 1995.

the actual and predicted value of NPD ratios using the regression coefficients in tables 17-19 when the categorical variable is set to the whole sample. Figure 1 is based on imputed profitability and shows a much faster rate of decline in NPD ratios than figure 2, which is based on reported profitability.

A more sophisticated method for assessing likely NPD ratios in future years for the whole sample is to build a few likely scenarios based on alternative assumptions about the possible NPD ratios for individual groups and the possible distribution of total liabilities. Table 20 outlines nine scenarios for the NPD ratios for the whole sample by the year 2007 by providing specific alternative assumptions about the possible NPD ratios for each group of enterprises and about the possible distribu- 
Figure 1. Predicting nonperforming debt ratios: Imputed profitability and weighted regression

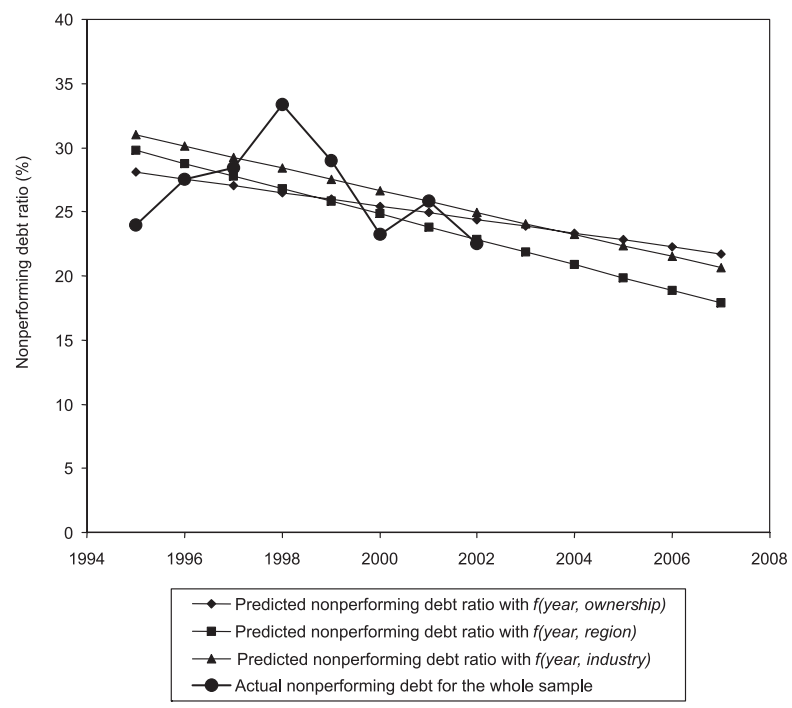

Figure 2. Predicting nonperforming debt ratios: Reported profitability and weighted regression

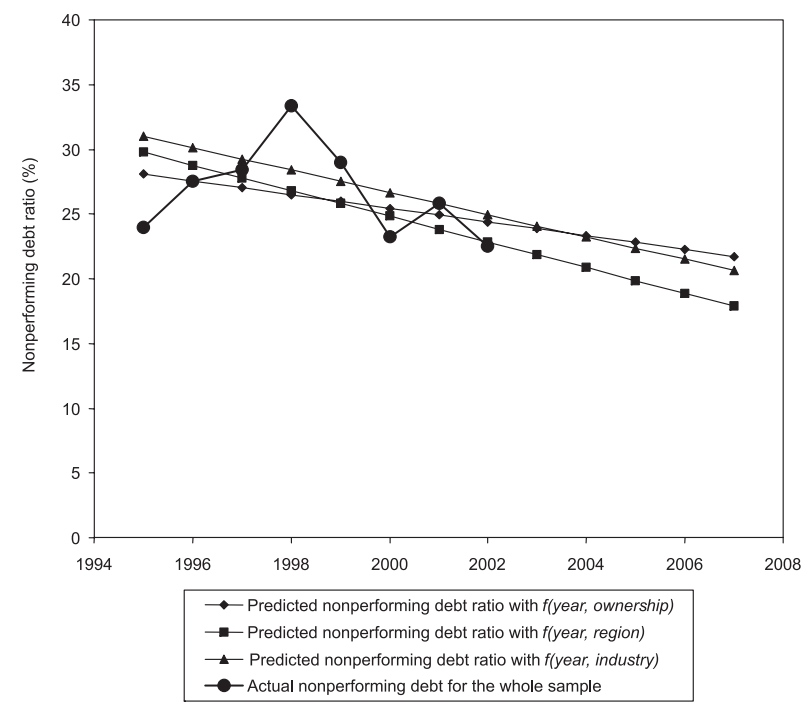


Nonperforming Debts in Chinese Enterprises

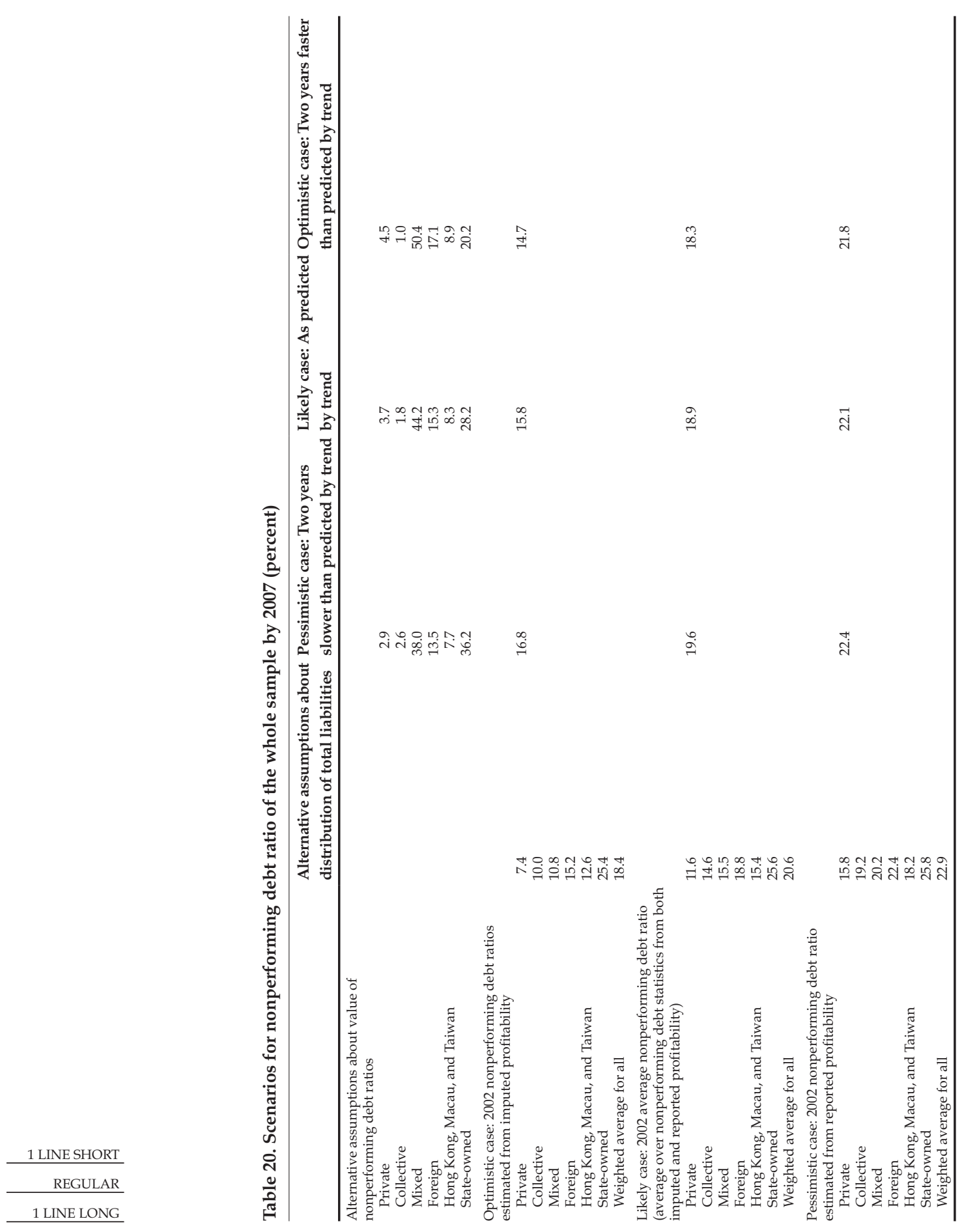


tion of total liabilities across groups. These simulated scenarios can facilitate policy debates by showing the magnitude of reforms necessary to achieve various specific objectives. For example, table 20 shows that to lower the overall NPD ratio to 14.7 percent by the year 2007, it is necessary for individual groups to achieve NPD ratios in the optimistic case (e.g., 2002 NPD ratios estimated from imputed profitability) and for the distribution of total liabilities also to achieve the optimistic case, in which the SOE sector share of total liabilities falls to 20.2 percent. The nine scenarios in table 20 are built for illustrative purposes. The alternative assumptions are subjective and debatable but are all based on the patterns of NPD statistics estimated in this paper.

\section{Explaining profitability and quality of debts}

The NPD statistics for each group of enterprises reflect the total effects from all factors that might cause NPD. For example, a major factor that might contribute to a high NPD ratio for SOEs is that many enterprises in the utilities industry are SOEs and the utilities industry as a whole is not profitable because of heavy price regulation by the government. In this case, the high NPD ratio for the group of SOEs actually reflects both ownership and industry risks. The purpose of this section is to use regression analysis to isolate different sources of bad debt risks. Because we have classified enterprise debts by their profitability, we need to explain what factors are driving enterprise profitability and returns on assets.

Tables 21 and 22 summarize the characteristics of the key variables used in the profitability regressions. Table 23 reports the results of four panel data regressions: two logistic regressions explaining the imputed and reported profitability and two linear regressions explaining the imputed and reported return on total assets. The explanatory variables for the four regressions are the same: $\log$ (capital/labor ratio); ratio of liability to total assets; $\log ($ employees); market share; industry concentration; and dummy variables for ownership, year, industry, and region. The coefficients and their standard errors indicate the size and the statistical significance of the impact of the explanatory variables on profitability.

Some common patterns emerge in all four regressions:

- The ratio of liability to total assets has a significantly negative impact on profitability, implying that the more the enterprise borrows, the less the profits or the lower the returns on assets.

- Market share has a positive impact on profitability.

- State ownership has a negative impact on profitability.

- Profitability improves significantly during 2000-2002. 
Nonperforming Debts in Chinese Enterprises

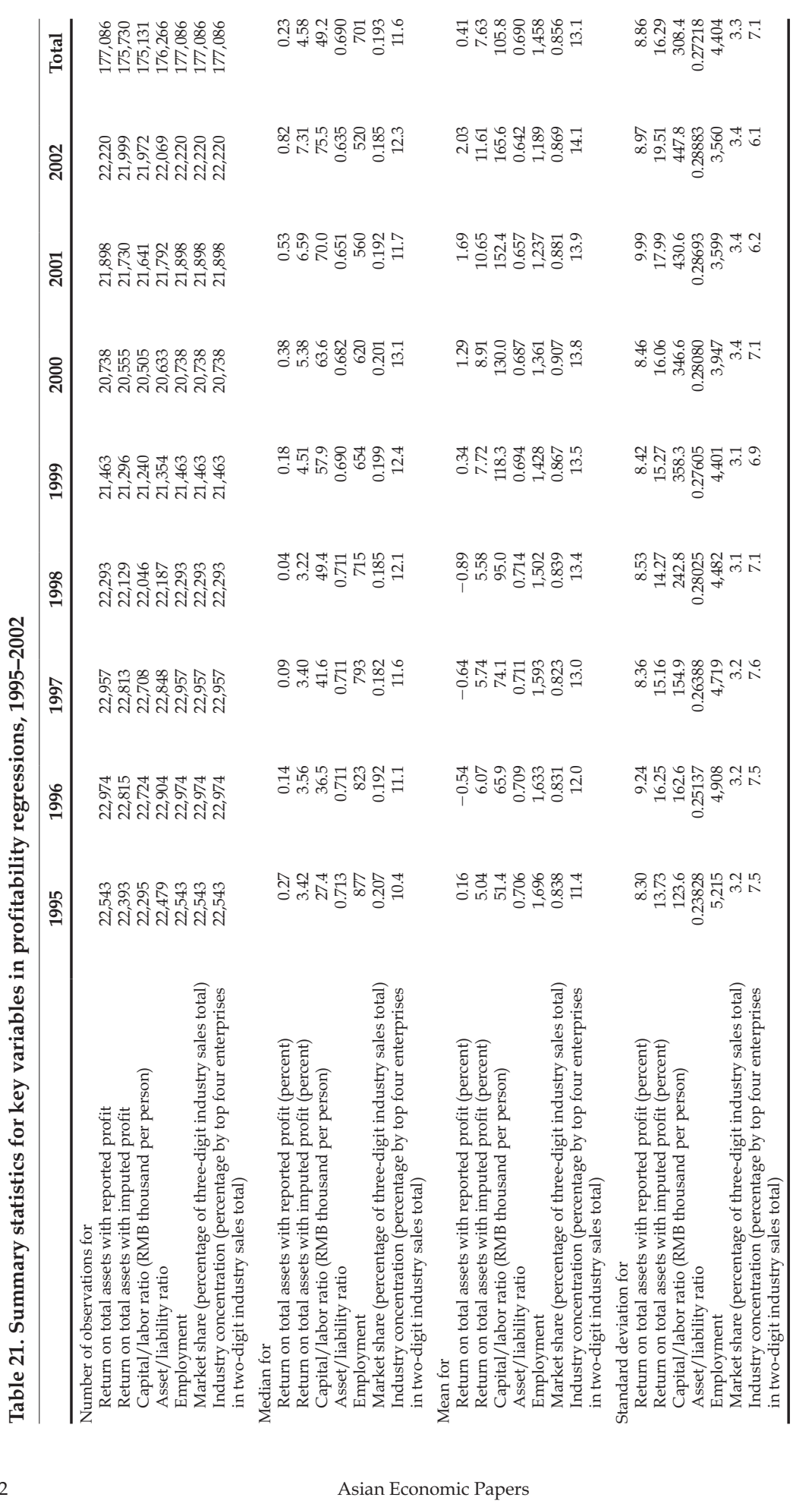

Asian Economic Papers (ASEP) 4:3 Job No. 1055

page 92 
Nonperforming Debts in Chinese Enterprises

Table 22. Median of key variables for profitability regressions by ownership, 1995-2002

\begin{tabular}{|c|c|c|c|c|c|c|c|c|c|}
\hline & 1995 & 1996 & 1997 & 1998 & 1999 & 2000 & 2001 & 2002 & Total \\
\hline \multicolumn{10}{|l|}{$\begin{array}{l}\text { Percentage return on total assets } \\
\text { with reported profit for }\end{array}$} \\
\hline Private & 1.78 & 4.84 & 0.36 & 0.03 & 1.00 & 1.03 & 1.38 & 1.72 & 1.34 \\
\hline Collective & 0.69 & 0.50 & 0.34 & 0.28 & 0.51 & 0.67 & 0.72 & 0.91 & 0.52 \\
\hline Mixed & 2.07 & 1.46 & 0.89 & 0.52 & 0.88 & 1.10 & 1.24 & 1.33 & 1.11 \\
\hline Foreign & 1.70 & 0.83 & 0.77 & 0.54 & 1.65 & 2.93 & 2.99 & 3.61 & 2.08 \\
\hline Hong Kong, Macau, and Taiwan & 1.31 & 1.01 & 0.89 & 0.43 & 0.87 & 1.35 & 1.55 & 1.95 & 1.26 \\
\hline State-owned & 0.14 & 0.05 & 0.02 & 0.00 & 0.03 & 0.09 & 0.06 & 0.09 & 0.05 \\
\hline Total & 0.27 & 0.14 & 0.09 & 0.04 & 0.18 & 0.38 & 0.53 & 0.82 & 0.23 \\
\hline \multicolumn{10}{|l|}{$\begin{array}{l}\text { Percentage return on total assets } \\
\text { with imputed profit for }\end{array}$} \\
\hline Private & 11.25 & 17.44 & 9.65 & 7.39 & 12.01 & 11.34 & 12.93 & 13.98 & 12.67 \\
\hline Collective & 7.44 & 8.24 & 7.17 & 7.52 & 8.60 & 9.46 & 10.57 & 10.97 & 8.41 \\
\hline Mixed & 7.13 & 6.78 & 6.36 & 6.06 & 7.11 & 7.83 & 8.83 & 9.43 & 7.85 \\
\hline Foreign & 5.80 & 6.31 & 6.09 & 5.49 & 8.15 & 9.93 & 11.01 & 11.24 & 8.66 \\
\hline Hong Kong, Macau, and Taiwan & 6.57 & 6.75 & 6.23 & 5.41 & 6.99 & 8.19 & 8.86 & 9.69 & 7.61 \\
\hline State-owned & 2.14 & 2.01 & 1.86 & 1.34 & 2.18 & 2.53 & 2.80 & 2.87 & 2.14 \\
\hline Total & 3.42 & 3.56 & 3.40 & 3.22 & 4.51 & 5.38 & 6.59 & 7.31 & 4.58 \\
\hline \multicolumn{10}{|l|}{$\begin{array}{l}\text { Capital/labor ratio (RMB thou- } \\
\text { sand per person) for }\end{array}$} \\
\hline Private & 26 & 54 & 49 & 48 & 52 & 51 & 52 & 56 & 52 \\
\hline Collective & 25 & 30 & 33 & 40 & 44 & 45 & 49 & 52 & 37 \\
\hline Mixed & 33 & 39 & 42 & 46 & 52 & 57 & 62 & 67 & 54 \\
\hline Foreign & 71 & 91 & 114 & 134 & 144 & 145 & 149 & 145 & 129 \\
\hline Hong Kong, Macau, and Taiwan & 63 & 79 & 82 & 98 & 109 & 108 & 107 & 103 & 96 \\
\hline State-owned & 26 & 35 & 40 & 47 & 55 & 62 & 68 & 74 & 44 \\
\hline Total & 27 & 36 & 42 & 49 & 58 & 64 & 70 & 75 & 49 \\
\hline \multicolumn{10}{|l|}{ Liability/total assets ratio for } \\
\hline Private & 0.531 & 0.653 & 0.722 & 0.724 & 0.686 & 0.693 & 0.667 & 0.654 & 0.671 \\
\hline Collective & 0.708 & 0.718 & 0.723 & 0.717 & 0.707 & 0.712 & 0.690 & 0.686 & 0.711 \\
\hline Mixed & 0.646 & 0.636 & 0.650 & 0.672 & 0.664 & 0.660 & 0.653 & 0.644 & 0.654 \\
\hline Foreign & 0.574 & 0.553 & 0.554 & 0.538 & 0.534 & 0.516 & 0.479 & 0.472 & 0.517 \\
\hline Hong Kong, Macau, and Taiwan & 0.638 & 0.622 & 0.625 & 0.614 & 0.603 & 0.589 & 0.544 & 0.520 & 0.583 \\
\hline State-owned & 0.731 & 0.733 & 0.737 & 0.747 & 0.732 & 0.732 & 0.718 & 0.704 & 0.732 \\
\hline Total & 0.713 & 0.711 & 0.711 & 0.711 & 0.690 & 0.682 & 0.651 & 0.635 & 0.690 \\
\hline \multicolumn{10}{|l|}{ Median employment per firm for } \\
\hline Private & 500 & 453 & 718 & 429 & 391 & 394 & 383 & 367 & 384 \\
\hline Collective & 643 & 599 & 565 & 511 & 490 & 461 & 437 & 408 & 528 \\
\hline Mixed & 1,010 & 972 & 897 & 820 & 748 & 711 & 645 & 606 & 725 \\
\hline Foreign & 408 & 387 & 376 & 350 & 321 & 332 & 320 & 320 & 341 \\
\hline Hong Kong, Macau, and Taiwan & 446 & 390 & 387 & 360 & 364 & 360 & 343 & 340 & 363 \\
\hline State-owned & 1,014 & 975 & 946 & 873 & 829 & 793 & 753 & 729 & 894 \\
\hline Total & 877 & 823 & 793 & 715 & 654 & 620 & 560 & 520 & 701 \\
\hline \multicolumn{10}{|l|}{$\begin{array}{l}\text { Market share (percentage of three- } \\
\text { digit industry sales total) for }\end{array}$} \\
\hline Private & 0.159 & 0.285 & 0.283 & 0.118 & 0.147 & 0.148 & 0.148 & 0.141 & 0.146 \\
\hline Collective & 0.206 & 0.190 & 0.175 & 0.193 & 0.192 & 0.185 & 0.161 & 0.146 & 0.185 \\
\hline Mixed & 0.361 & 0.310 & 0.253 & 0.212 & 0.221 & 0.213 & 0.198 & 0.183 & 0.214 \\
\hline Foreign & 0.450 & 0.402 & 0.399 & 0.419 & 0.406 & 0.396 & 0.355 & 0.318 & 0.381 \\
\hline Hong Kong, Macau, and Taiwan & 0.339 & 0.331 & 0.341 & 0.341 & 0.329 & 0.343 & 0.312 & 0.277 & 0.318 \\
\hline State-owned & 0.185 & 0.169 & 0.156 & 0.149 & 0.158 & 0.155 & 0.145 & 0.143 & 0.160 \\
\hline Total & 0.207 & 0.192 & 0.182 & 0.185 & 0.199 & 0.201 & 0.192 & 0.185 & 0.193 \\
\hline \multicolumn{10}{|l|}{$\begin{array}{l}\text { Industry concentration (percent- } \\
\text { age by top four enterprises in two- } \\
\text { digit industry sales total) for }\end{array}$} \\
\hline Private & 12.6 & 9.5 & 8.6 & 10.8 & 11.7 & 11.0 & 11.6 & 11.1 & 11.6 \\
\hline Collective & 9.9 & 8.5 & 9.7 & 10.8 & 10.6 & 11.3 & 11.6 & 11.1 & 10.5 \\
\hline Mixed & 10.5 & 11.3 & 11.6 & 11.7 & 12.4 & 12.9 & 11.7 & 12.3 & 11.8 \\
\hline Foreign & 10.5 & 11.3 & 13.3 & 12.5 & 13.8 & 13.1 & 14.0 & 12.3 & 12.4 \\
\hline Hong Kong, Macau, and Taiwan & 9.9 & 10.6 & 11.6 & 12.1 & 12.4 & 12.1 & 13.1 & 12.3 & 11.7 \\
\hline State-owned & 10.4 & 11.1 & 11.6 & 12.1 & 12.4 & 13.4 & 13.1 & 12.5 & 11.7 \\
\hline Total & 10.4 & 11.1 & 11.6 & 12.1 & 12.4 & 13.1 & 11.7 & 12.3 & 11.6 \\
\hline
\end{tabular}




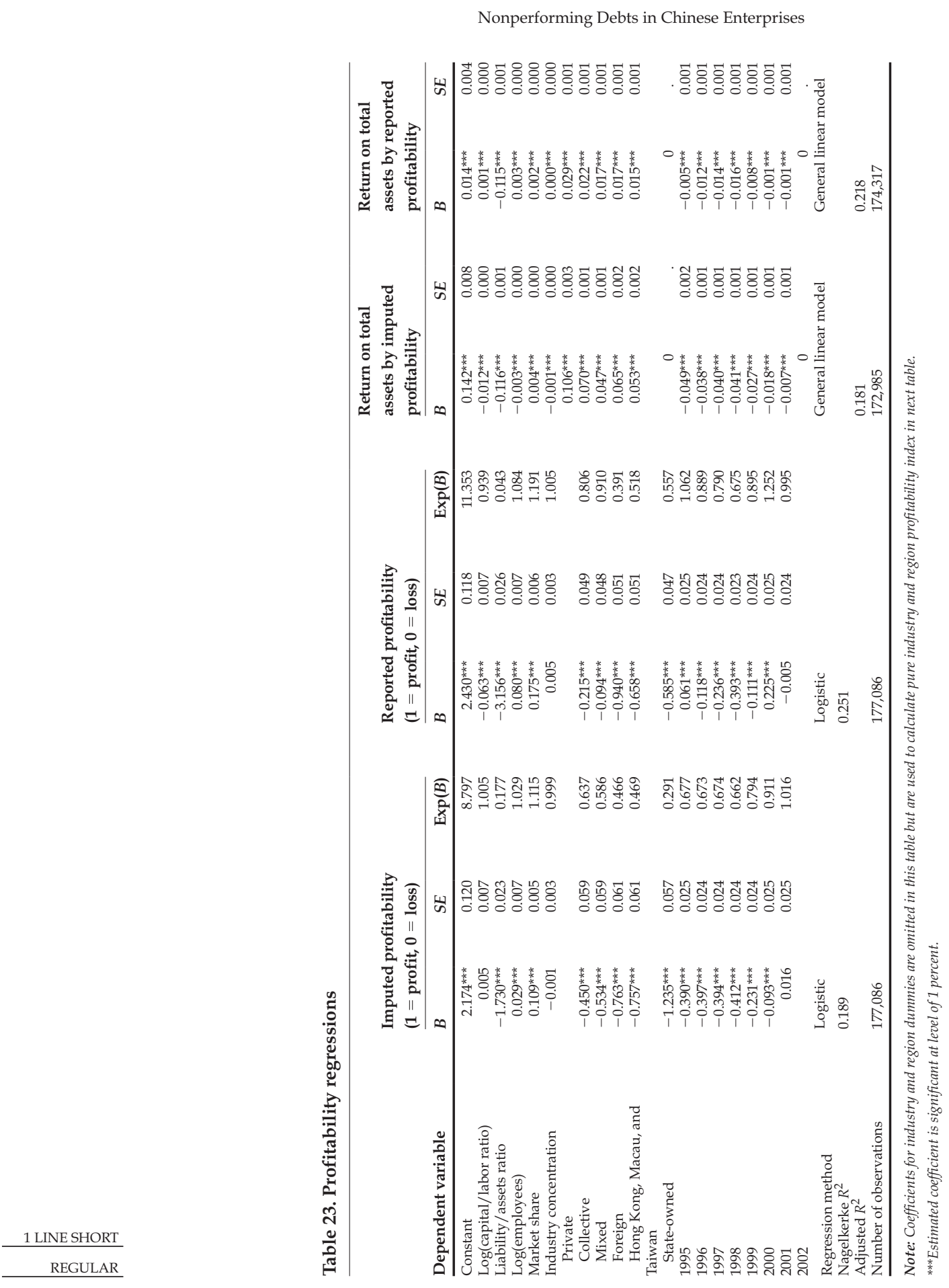


Nonperforming Debts in Chinese Enterprises
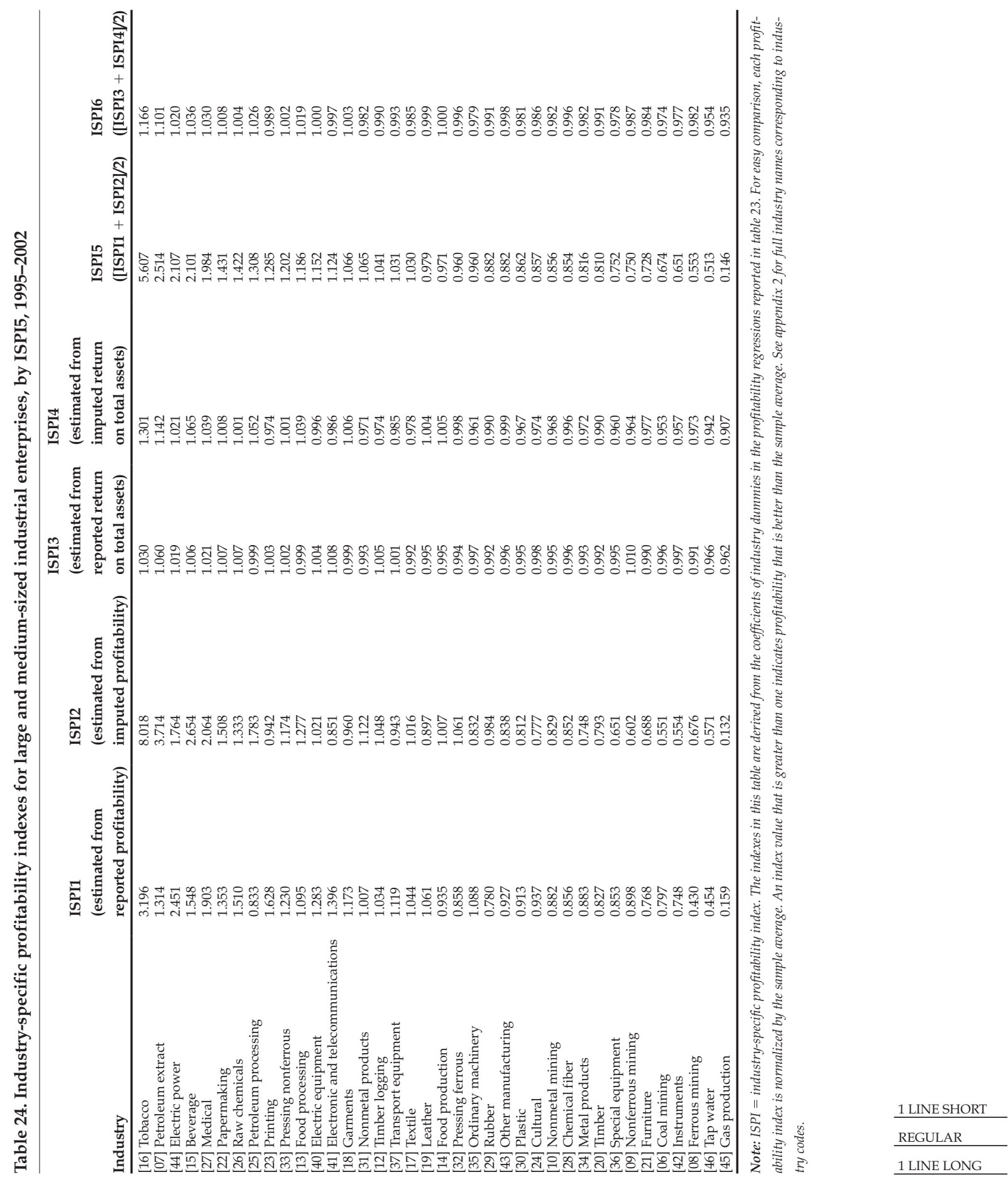

Asian Economic Papers

Asian Economic Papers (ASEP) 4:3 Job No. 1055

page 95 
It should be noted that the above are independent impacts by each explanatory variable after the impacts of other explanatory variables, including the impact of industry and region variables, are controlled for.

The impacts of ownership on profitability revealed by each of the four regressions are the following:

- The logistic regression on imputed profitability implies that, compared to private enterprises, the odds that collective, mixed, foreign, HK-M-Taiwan, and SOEs will be profitable are $0.637,0.586,0.466,0.469$, and 0.291 , respectively. In other words, the SOEs have the lowest probability of making profits compared with the other groups.

- The logistic regression on reported profitability shows similar results but with less dramatic quantitative impacts except for the foreign-invested and HK-M-Taiwaninvested enterprises. As compared to private enterprises, the odds that collective, mixed, foreign, HK-M-Taiwan, and SOEs will be profitable are 0.806, 0.910, 0.391, 0.518 , and 0.557 , respectively. The foreign-invested and HK-M-Taiwan-invested enterprises seem less profitable than the SOEs when measured by reported profits. This is likely attributable to the different tax and accounting system for the externally invested enterprises. For example, the multinational corporations are likely to use various accounting practices to transfer profits to their overseas entities. The imputed profits would be more useful when comparing enterprise performance across ownership in China because they are derived from the consistent framework of calculating value-added and would not be affected by differences in tax and accounting systems across ownership sectors.

- The linear regression on imputed profitability shows that the return on total assets for private, collective, mixed, foreign, and HK-M-Taiwan enterprises will be 10.6, $7,4.7,6.5$, and 5.3 percentage points higher, respectively, than that for SOEs.

- The linear regression on reported profitability shows that the return on total assets for private, collective, mixed, foreign, and HK-M-Taiwan enterprises will be $2.9,2.2,1.7,1.7$, and 1.5 percentage points higher, respectively, than that for SOEs.

Tables 24 and 25 use the industry and region dummies in the four profitability regressions to construct industry- and region-specific profitability indexes (ISPI and RSPI, respectively). These tables can be used as benchmarks for assessing the pure industry-specific or region-specific risks of enterprise debts in China. They summarize the independent impacts of industry and location on the quality of industrial enterprise debts averaged over 1995-2002.

REGULAR

1 LINE LONG 
Nonperforming Debts in Chinese Enterprises

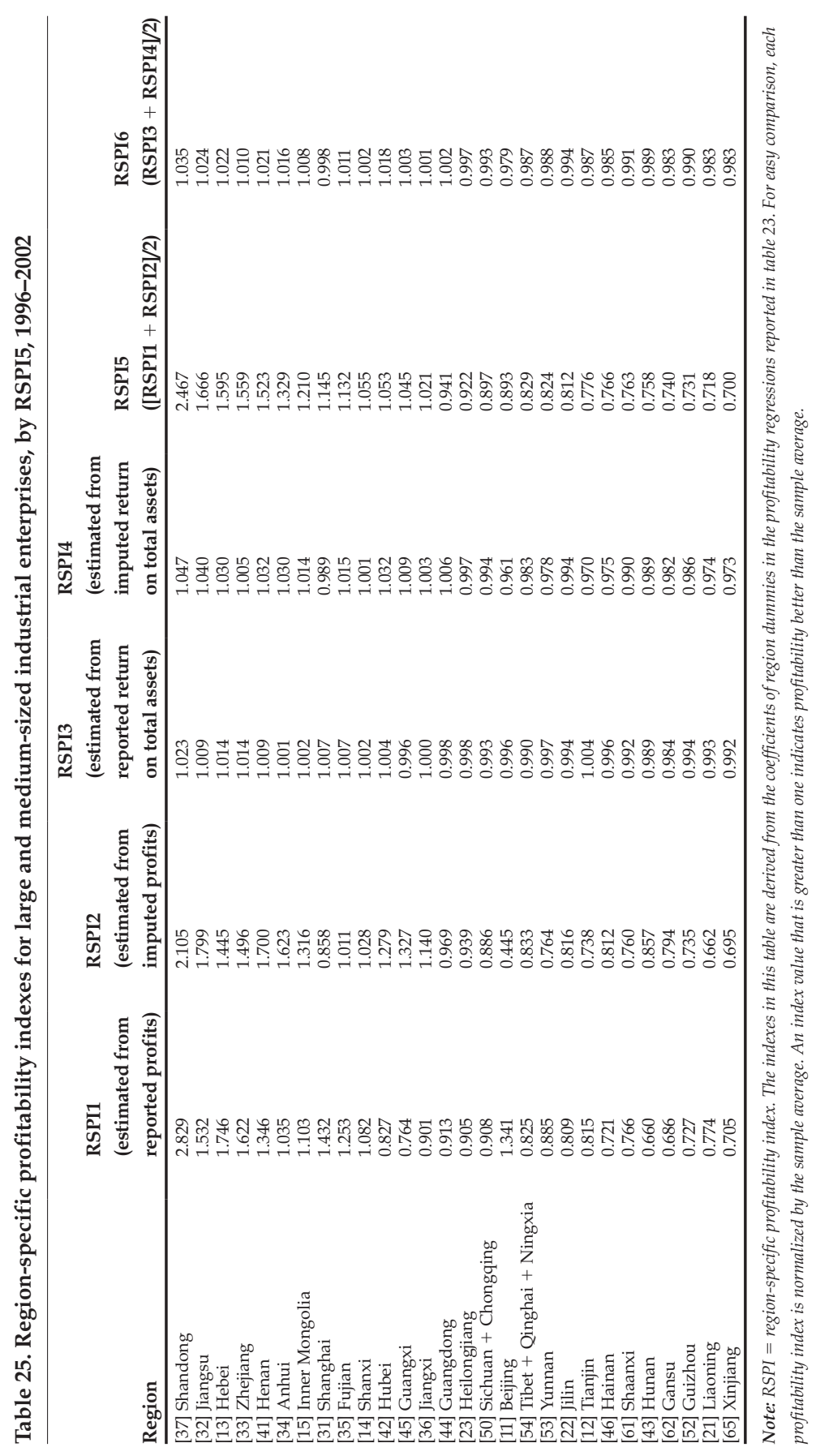

1 LINE SHORT 
ISPI1, ISPI2, ISPI5, RSPI1, RSPI2, and RSPI5 (see tables 24 and 25) are derived from the industry or region dummies in the logistic regressions but are normalized by the sample average. Compared with the sample average, the odds that a specific industry or region will be profitable can be calculated by multiplying the sample average by the index value. For example, the index value of ISPI5 given in table 24 for the tobacco industry is 5.607. Thus the odds that the tobacco industry will be profitable, are 5.607 times those that the average industry will be profitable, when other factors influencing profitability are held constant.

ISPI3, ISPI4, ISPI6, RSPI3, RSPI4, and RSPI6 are derived from the industry or region dummies in the linear regressions but are also normalized by first subtracting the average return of all industries or regions and then adding one. This makes the index value equal to one for the average of all industries or regions. The index value minus one is the additional return a specific industry or region has over the average return on total assets. For example, the index value of ISPI6 in table 24 is 1.166 for the tobacco industry. This means that the tobacco industry's return on total assets is likely to be higher than the average return on total assets for all industries by a ratio of $0.166(1.166-1)$, or 16.6 percent.

Hence, tables 24 and 25 help us determine which industries and regions are more profitable for the large and medium-sized industrial enterprises when the influences of other factors such as types of ownership and capital intensity are removed. The two tables are sorted by ISPI5 and RSPI5 from high to low profitability. The top five industries by industry-specific profitability are tobacco processing; petroleum and natural gas extraction; electric power, steam, and hot water; beverage production; and medical and pharmaceutical products. The top five regions by region-specific profitability are Shandong, Jiangsu, Hebei, Zhejiang, and Henan.

The profitability regressions in table 23 can also be used to assess the profitability or debt quality of a particular enterprise if we know the value for that enterprise of the explanatory variable. The predicted value from the logistic regressions is the probability of making profits. Of course, the prediction using the regression equation only helps to assess non-enterprise-specific risks that are summarized by the explanatory variables in the regressions. In the real world and for a specific enterprise, the enterprise-specific risks are clearly most important and cannot be analyzed using the statistical results presented here. It is usually the case, however, that practitioners know the firm-specific risks very well but find it difficult to assess non-firmspecific risks. Our study helps reveal non-firm-specific information and thus can contribute to better policy and more effective business strategy. 


\section{Exit of poor-performing enterprises and its impact on the NPD ratio}

The analysis in the previous sections is affected by a sample selection bias that results from the way the National Bureau of Statistics in China defines the sample of large and medium-sized industrial enterprises. As pointed out earlier, about 20 percent of firms enter and exit this sample every year, and the enterprises in the sample make up a very dynamic group that accurately reflects the current state of China's large industrial enterprise sector. Such change in the sample, however, creates a problem for measuring the NPD ratio: it is possible that the exiting enterprises have higher NPD ratios than the new entries.

Table 26 shows the number of enterprises by profitability and entry-exit status for the 1995-2002 period. The entry-exit status of a sample enterprise for a particular period $t$ is defined as one of the following four exclusive groups: ${ }^{1}$

- "exit" group: the enterprise was in the sample at $t-1$ and $t$, but not at $t+1$

- "new" group: the enterprise was in the sample at $t$ and $t+1$, but not at $t-1$

- "stay" group: the enterprise was in the sample at $t-1, t$, and $t+1$

- "once" group: the enterprise was in the sample at $t$, but not at $t-1$ and $t+1$

As shown in table 26, among the profit-making enterprises in 1996, 1,177 enterprises appeared in the sample of 1995 and 1996 but did not show up in the sample of 1997, and hence they belong to the "exit" group; 2,802 enterprises did not appear in the sample of 1995 but appeared in the sample of 1996 and 1997, and hence they fall into the "new" group; 10,540 enterprises appeared in the sample of 1995, 1996, and 1997, and hence they are in the "stay" group; 516 enterprises did not appear in 1995 and 1997 but showed up in 1996, and hence they are put into the "once" group.

Table 26 tells us that both profit-making and loss-making enterprises are actively entering and exiting the sample every year. The dynamics of this life-death process reflect how lively China's enterprise reform and restructuring has been. But we would expect that the "exit" group would have more loss-making enterprises than the "new" or "stay" group. The bottom part of table 26 presents information to al-

1 Because we do not have data for 1995 and 2003, the entry-exit status for 1995 and 2003 may differ slightly from the definition here. For 1995, we have information on firms that exited or stayed in 1996, but we do not have information on firms that were new in 1995 or appeared only in 1995. For 2002, we have information on firms that were new or stayed in 2002, but we have no information on firms that exited or appear only in 2002. The unavailable information is indicated by blank entries in the table. 
Nonperforming Debts in Chinese Enterprises

Table 26. Number of enterprises by profitability and entry-exit status, 1995-2002

\begin{tabular}{|c|c|c|c|c|c|c|c|c|}
\hline & 1995 & 1996 & 1997 & 1998 & 1999 & 2000 & 2001 & 2002 \\
\hline \multicolumn{9}{|c|}{ Number of profit-making enterprises } \\
\hline Exit & 2,485 & 1,177 & 2,434 & 1,648 & 1,335 & 2,608 & 1,258 & \\
\hline New & & 2,802 & 1,533 & 2,408 & 2,523 & 1,160 & 3,890 & 2,300 \\
\hline Stay & 12,229 & 10,540 & 10,493 & 9,849 & 11,017 & 11,235 & 11,221 & 14,968 \\
\hline Once & & 516 & 599 & 710 & 368 & 378 & 565 & \\
\hline Whole sample & 14,714 & 15,035 & 15,059 & 14,615 & 15,243 & 15,381 & 16,934 & 17,268 \\
\hline \multicolumn{9}{|c|}{ Number of loss-making enterprises } \\
\hline Exit & 1,651 & 1,048 & 1,745 & 1,722 & 943 & 1,182 & 649 & \\
\hline New & & 981 & 574 & 838 & 642 & 360 & 864 & 687 \\
\hline Stay & 6,178 & 5,642 & 5,293 & 4,674 & 4,474 & 3,631 & 3,258 & 4,265 \\
\hline Once & & 268 & 286 & 444 & 161 & 184 & 193 & \\
\hline Whole sample & 7,829 & 7,939 & 7,898 & 7,678 & 6,220 & 5,357 & 4,964 & 4,952 \\
\hline \multicolumn{9}{|c|}{ Number of enterprises } \\
\hline Exit & 4,136 & 2,225 & 4,179 & 3,370 & 2,278 & 3,790 & 1,907 & \\
\hline New & & 3,783 & 2,107 & 3,246 & 3,165 & 1,520 & 4,754 & 2,987 \\
\hline Stay & 18,407 & 16,182 & 15,786 & 14,523 & 15,491 & 14,866 & 14,479 & 19,233 \\
\hline Once & & 784 & 885 & 1,154 & 529 & 562 & 758 & \\
\hline Whole sample & 22,543 & 22,974 & 22,957 & 22,293 & 21,463 & 20,738 & 21,898 & 22,220 \\
\hline \multicolumn{9}{|c|}{ Share of loss-making enterprises (percent) } \\
\hline Exit & 39.9 & 47.1 & 41.8 & 51.1 & 41.4 & 31.2 & 34.0 & \\
\hline New & & 25.9 & 27.2 & 25.8 & 20.3 & 23.7 & 18.2 & 23.0 \\
\hline Stay & 33.6 & 34.9 & 33.5 & 32.2 & 28.9 & 24.4 & 22.5 & 22.2 \\
\hline Once & & 34.2 & 32.3 & 38.5 & 30.4 & 32.7 & 25.5 & \\
\hline Whole sample & 34.7 & 34.6 & 34.4 & 34.4 & 29.0 & 25.8 & 22.7 & 22.3 \\
\hline
\end{tabular}

Note: "Exit" group = enterprise was in sample at $t-1$ and $t$ but not at $t+1$; "new" group = enterprise was in sample at $t$ and $t+1$ but not at $t-1$; "stay" group = enterprise was in sample at $t-1, t$, and $t+1$; "once" group $=$ enterprise was in sample at $t$, but not at $t-1$ or $t+1$

low us to assess this expectation. The share of loss-making enterprises in the "exit" group is much higher than their share in the other groups, particularly during 199899. In 1998, the share of loss-making firms is 51.1 percent for the "exit" group, 25.8 percent for the "new" group, 32.2 percent for the "stay" group, and 38.5 percent for the "once" group. Clearly the group that is exiting the sample has a much higher share of poor-performing firms than the group that is entering the sample. This is a good trend for the economy, but it creates biased estimates of NPD ratios, because the NPDs of the exiting enterprises are entirely ignored in the analysis of the previous sections.

Unlike table 26, which shows the distribution in the number of enterprises by entryexit status, table 27 shows the distribution of the amounts of performing and nonperforming debts by entry-exit status. For example, table 27 shows that the amount of NPDs that exited the sample with the exit of enterprises rose from RMB157 billion in 1995 to RMB200 billion in 1998, and then fell to RMB92 billion in 2001. On the other hand, the amount of performing debt that entered the sample with the entry of new enterprises rose steadily from RMB311 billion in 1996 to RMB400-800 billion after 1997. The exit of bad firms and the entry of good firms are clearly driving forces in improving the debt quality of the Chinese enterprise sector. 
Nonperforming Debts in Chinese Enterprises

Table 27. Liabilities/debts by profitability and entry-exit status, 1995-2002

\begin{tabular}{|c|c|c|c|c|c|c|c|c|}
\hline & 1995 & 1996 & 1997 & 1998 & 1999 & 2000 & 2001 & 2002 \\
\hline \multicolumn{9}{|c|}{$\begin{array}{l}\text { Amount of performing debt based on } \\
\text { imputed profits (RMB billion) }\end{array}$} \\
\hline Exit & 327 & 204 & 384 & 272 & 396 & 512 & 298 & \\
\hline New & & 311 & 248 & 503 & 429 & 418 & 780 & 483 \\
\hline Stay & 2,043 & 2,044 & 2,295 & 2,335 & 2,587 & 2,812 & 3,088 & 4,190 \\
\hline Once & & 52 & 70 & 129 & 78 & 92 & 71 & \\
\hline Whole sample & 2,370 & 2,611 & 2,997 & 3,239 & 3,490 & 3,834 & 4,237 & 4,673 \\
\hline \multicolumn{9}{|c|}{$\begin{array}{l}\text { Amount of nonperforming debt based } \\
\text { on imputed profits (RMB billion) }\end{array}$} \\
\hline Exit & 157 & 116 & 193 & 200 & 154 & 174 & 92 & \\
\hline New & & 130 & 96 & 145 & 151 & 81 & 168 & 115 \\
\hline Stay & 757 & 826 & 881 & 971 & 990 & 848 & 803 & 936 \\
\hline Once & & 23 & 34 & 54 & 20 & 25 & 27 & \\
\hline Whole sample & 914 & 1,095 & 1,204 & 1,370 & 1,315 & 1,128 & 1,090 & 1,051 \\
\hline \multicolumn{9}{|c|}{ Total liabilities (RMB billion) } \\
\hline Exit & 484 & 320 & 577 & 472 & 550 & 686 & 390 & \\
\hline New & & 441 & 344 & 648 & 580 & 499 & 948 & 598 \\
\hline Stay & 2,800 & 2,870 & 3,176 & 3,306 & 3,577 & 3,660 & 3,891 & 5,126 \\
\hline Once & & 75 & 104 & 183 & 98 & 117 & 98 & \\
\hline Whole sample & 3,284 & 3,706 & 4,201 & 4,609 & 4,805 & 4,962 & 5,327 & 5,724 \\
\hline \multicolumn{9}{|c|}{$\begin{array}{l}\text { Nonperforming debt ratio based on } \\
\text { imputed profits (percent) }\end{array}$} \\
\hline Exit & 32.4 & 36.3 & 33.4 & 42.4 & 28.0 & 25.4 & 23.6 & \\
\hline New & & 29.5 & 27.9 & 22.4 & 26.0 & 16.2 & 17.7 & 19.2 \\
\hline Stay & 27.0 & 28.8 & 27.7 & 29.4 & 27.7 & 23.2 & 20.6 & 18.3 \\
\hline Once & & 30.7 & 32.7 & 29.5 & 20.4 & 21.4 & 27.6 & \\
\hline Whole sample & 27.8 & 29.5 & 28.7 & 29.7 & 27.4 & 22.7 & 20.5 & 18.4 \\
\hline
\end{tabular}

Note: "Exit" group = enterprise was in sample at $t-1$ and t but not at $t+1$; "new" group = enterprise was in sample at $t$ and $t+1$ but not at $t-1$; "stay" group = enterprise was in sample at $t-1$, $t$, and $t+1$; "once" group = enterprise was in sample at $t$, but not at $t-1$ or $t+1$.

From table 27 it is clear that the NPD ratio for the "exit" group is much higher than that for the "new," "stay," and "once" groups. For example, in 1998 the NPD ratio for the "exit" group was 42.4 percent, close to twice the NPD ratio for the "new" group (22.4 percent) and much higher than that for the "stay" group (29.4 percent).

The implication of the above evidence is that the dynamics of entry and exit is contributing significantly to the fall in the NPD ratio for the sample. Clearly, the analysis in the previous sections underestimated the level of the NPD ratios. The number of bad firms exiting the sample, however, is more than the number of bad firms entering the sample for every one of the eight years. This means that the trend of declining NPD, as revealed in the previous sections, is still valid, although some bias and distortions exist in the level of estimated NPD. The rest of this section attempts to identify the size of the NPD ratio bias that resulted from the entry-exit dynamics of the sample enterprises.

If the "exit" group of enterprises had remained in the sample while the same NPD ratio and the same amount of total debts were maintained, then the NPD ratio of the enlarged hypothetical sample would certainly have been pushed higher. Table 28 at- 
tempts to estimate how much higher the NPD ratio of the enlarged hypothetical sample would have been if the "exit" group had stayed in the sample for one, two, or three years. The variables in table 28 are defined as follows:

$R(t)=$ NPD ratio for the original sample for period $t$, from row 4 of table 6 .

$L(t)=$ total liabilities or debts of the original sample for period $t$, from row 7 of table 1 .

$R x(t)=$ NPD ratio for the "exit" group for period $t$, from row 16 of table 27.

$L x(t)=$ total liabilities/debts for the "exit" group for period $t$, from row 11 of table 27 .

$R(t, T)=$ NPD ratio for the hypothetically enlarged sample, with the original "exit" group remaining in the sample for $T$ periods:

$$
R(t, T)=\left[R(t) * L(t)+\Sigma_{j} R x(t-j) * L x(t-j)\right] /\left[L(t)+\Sigma_{j} L x(t-j)\right],
$$

where $j=1,2, \ldots, T . d R(t, T)=R(t, T)-R(t)$, the difference, in percentage points, in the estimated NPD ratios between the enlarged hypothetic sample and the original sample.

In table 28, rows 1-4 simply replicate results we have from previous tables, as noted above. Rows 5-10 construct the NPD ratio and the total debts of the "exit" group for the periods $t-1, t-2$, and $t-3$. These 10 rows of data are used to calculate the NPD ratio for the enlarged hypothetical sample in which the "exit" group of enterprises are retained for one, two, or three periods. The results of these calculations are shown in rows 11-13. The longer the "exit" group is retained in the enlarged sample, the higher the NPD ratio for the enlarged sample. Rows 14-16 show the percentage-point difference in the NPD ratio between the enlarged hypothetical sample (i.e., including the "exit" group) and the original sample. This is the estimated sample selection bias. As shown in table 28, on average, over 1998-2002, the NPD ratio would have increased about two percentage points if the "exit" group of enterprises had remained in the sample for three more years.

As shown in row 16 of table 28, the increase in the NPD ratio in this counterfactual experiment is particularly significant for the years 1999 to 2001, largely as a result of more active restructuring of SOEs during this period. We know that during the period from 1999 to 2000, Chinese authorities transferred RMB1.4 trillion in bad loans from the four big state-owned banks to four asset management companies to facilitate the bankruptcies and restructuring of SOEs. The exit of poor-performing enterprises and their debts from our sample was also very significant around 1998. In fact, as shown in row 6 of table 27, from 1995 to 2000, RMB0.994 trillion in NPDs (based on the imputed-profits method of this paper) exited from our sample, 
Table 28. Reduction of nonperforming debt ratio resulting from exit of poor-performing enterprises, 1995-2002

\begin{tabular}{|c|c|c|c|c|c|c|c|c|c|c|c|}
\hline Row & Variable & Definition of variable & 1995 & 1996 & 1997 & 1998 & 1999 & 2000 & 2001 & 2002 & $\begin{array}{l}\text { Average } \\
\text { during } \\
\text { 1998-2002 }\end{array}$ \\
\hline 1 & $R(t)$ & $\begin{array}{l}\text { Nonperforming debt ratio for } \\
\text { original sample in } t\end{array}$ & $27.8 \%$ & $29.5 \%$ & $28.7 \%$ & $29.7 \%$ & $27.4 \%$ & $22.7 \%$ & $20.5 \%$ & $18.4 \%$ & $23.7 \%$ \\
\hline 2 & $L(t)$ & Total debts for original sample & 3,286 & 3,707 & 4,201 & 4,610 & 4,805 & 4,963 & 5,329 & 5,722 & \\
\hline 3 & $R x(t)$ & $\begin{array}{l}\text { Nonperforming debt ratio for } \\
\text { "exit" group in } t\end{array}$ & $32.4 \%$ & $36.3 \%$ & $33.4 \%$ & $42.4 \%$ & $28.0 \%$ & $25.4 \%$ & $23.6 \%$ & & \\
\hline 4 & $L x(t)$ & $\begin{array}{l}\text { Total liabilities/debts for } \\
\text { "exit" group in } t\end{array}$ & 484 & 320 & 577 & 472 & 550 & 686 & 390 & & \\
\hline 5 & $R x(t-1)$ & $\begin{array}{l}\text { Nonperforming debt ratio for } \\
\text { "exit" group in } t-1\end{array}$ & & $32.4 \%$ & $36.3 \%$ & $33.4 \%$ & $42.4 \%$ & $28.0 \%$ & $25.4 \%$ & $23.6 \%$ & $30.6 \%$ \\
\hline 6 & $L x(t-1)$ & $\begin{array}{l}\text { Total debts for "exit" group in } \\
t-1\end{array}$ & & 484 & 320 & 577 & 472 & 550 & 686 & 390 & \\
\hline 7 & $R x(t-2)$ & $\begin{array}{l}\text { Nonperforming debt ratio for } \\
\text { "exit" group in } t-2\end{array}$ & & & $32.4 \%$ & $36.3 \%$ & $33.4 \%$ & $42.4 \%$ & $28.0 \%$ & $25.4 \%$ & $33.1 \%$ \\
\hline 8 & $L x(t-2)$ & $\begin{array}{l}\text { Total debts for "exit" group in } \\
t-2\end{array}$ & & & 484 & 320 & 577 & 472 & 550 & 686 & \\
\hline 9 & $R x(t-3)$ & $\begin{array}{l}\text { Nonperforming debt ratio for } \\
\text { "exit" group in } t-3\end{array}$ & & & & $32.4 \%$ & $36.3 \%$ & $33.4 \%$ & $42.4 \%$ & $28.0 \%$ & $34.5 \%$ \\
\hline 10 & $L x(t-3)$ & $\begin{array}{l}\text { Total debts for "exit" group in } \\
t-3\end{array}$ & & & & 484 & 320 & 577 & 472 & 550 & \\
\hline 11 & $R(t, 1)$ & $\begin{array}{l}\text { Nonperforming debt ratio of } \\
\text { enlarged sample with "exit" } \\
\text { group staying hypothetically } \\
\text { for one period }\end{array}$ & & $29.9 \%$ & $29.2 \%$ & $30.1 \%$ & $28.7 \%$ & $23.3 \%$ & $21.0 \%$ & $18.7 \%$ & $24.4 \%$ \\
\hline 12 & $R(t, 2)$ & $\begin{array}{l}\text { Nonperforming debt ratio of } \\
\text { enlarged sample with "exit" } \\
\text { group staying hypothetically } \\
\text { for two periods }\end{array}$ & & & $29.5 \%$ & $30.5 \%$ & $29.2 \%$ & $24.8 \%$ & $21.6 \%$ & $19.4 \%$ & $25.1 \%$ \\
\hline 13 & $R(t, 3)$ & $\begin{array}{l}\text { Nonperforming debt ratio of } \\
\text { enlarged sample with "exit" } \\
\text { group staying hypothetically } \\
\text { for three periods }\end{array}$ & & & & $30.7 \%$ & $29.5 \%$ & $25.5 \%$ & $23.0 \%$ & $20.0 \%$ & $25.7 \%$ \\
\hline 14 & $d R(t, 1)$ & $=d R(t, 1)-R(t)$ & & $0.3 \%$ & $0.5 \%$ & $0.4 \%$ & $1.3 \%$ & $0.5 \%$ & $0.6 \%$ & $0.3 \%$ & $0.6 \%$ \\
\hline 15 & $d R(t, 2)$ & $=d R(t, 2)-R(t)$ & & & $0.9 \%$ & $0.8 \%$ & $1.8 \%$ & $2.0 \%$ & $1.1 \%$ & $1.0 \%$ & $1.4 \%$ \\
\hline 16 & $d R(t, 3)$ & $=d R(t, 3)-R(t)$ & & & & $0.9 \%$ & $2.2 \%$ & $2.8 \%$ & $2.5 \%$ & $1.7 \%$ & $2.0 \%$ \\
\hline
\end{tabular}

Note: Exit group $=$ enterprise was in sample at $t-1$ and $t$ but not at $t+1$.

amounting to about 70 percent of the bad loans carved out by the four asset management companies. The declining trend of NPD ratios observed in the sample during 1995-2002 is clearly helped by the exit of these poor-performing enterprises and their NPDs. But as shown in row 13 of table 28, even if the "exit" group of enterprises had been included in the sample, the estimated NPD ratio for the hypothetically enlarged sample would still have declined very significantly, from 30.7 percent in 1998 to 20.0 percent in 2002, consistent with the trend we discovered in the previous sections.

The NPDs of "exiting" enterprises will continue to burden China's banks unless the banks can transfer the NPLs to China's asset management companies (which have been established to manage NPLs). So it is important to examine the impact of exiting poor-performing firms on estimated NPD ratios. It is also important, however, 
to keep in mind that past NPDs are sunk costs, and what matters the most for economic growth in China is the future trend of NPD ratios. Our NPD estimation method is more meaningful for projecting the future NPD trend because our sample consists of a truly dynamic group of the more active Chinese industrial enterprises, and these firms more accurately represent the current state of the Chinese industrial sector.

\section{Implications for banking reform}

This paper investigates empirically the quality of debts in the most dynamic group of enterprises in China. We uncover a large amount of independent, consistent, and statistically significant micro-level evidence that shows that the quality of enterprise debts in China improved during 1995-2002, especially after 1998. Because of the transparency and scientific methods used in this research, the evidence looks much more convincing than the macroeconomic statistics announced by China's financial authorities.

The fall in NPD ratios for our sample enterprises is brought about by the shift of financial resources from SOEs to NSEs, improvement in the profitability of SOEs and NSEs, and the exit of poor-performing enterprises from the sample of the large and medium-sized industrial enterprises. Both enterprise restructuring and the timing of business cycles have contributed to the recent improvement in enterprise profitability in China and the fall in NPD ratios. But the benefits of reform dividends and business cycle timing could be uncertain in the future.

China can continue, however, to benefit from the shift of financial resources from SOEs to better-performing NSEs, because the gaps in performance between the two are still very large. The gaps in profitability across industries and regions in China are also large, showing the need for better risk management and more efficient allocation of financial resources. The analysis in this paper could contribute to better assessment of various risks relating to ownership, industry, and region.

The rising share of financial resources allocated to NSEs and the declining NPD ratios for all types of enterprises provide excellent opportunities for pushing banking reforms in China now. If China's banks can establish good corporate governance and risk management, there seem to be enough good NSEs to lend to.

Most of the major banks in China, however, are still state-owned. In light of the strong evidence that SOEs are performing much worse than NSEs, priorities for banking reform would seem to be the development of good private banks, the pri- 
vatization of state-owned banks, and the encouragement of more foreign or jointventure banks to establish themselves in China. If China fails to develop non-state banks, there is a high risk that it will continue to have high NPL ratios, even when its NPD ratio is falling as a result of the privatization of enterprises. This is because SOEs could create NPLs in spite of the good performance of China's enterprise sector.

\section{Appendix I. Data cleaning}

The NBS survey covers more than 20,000 large and medium-sized industrial enterprises in China. It contains some observations that are unusable because of incomplete data reporting or the classification of small enterprises that were considered large and medium-sized historically on the basis of their design production capacity. The classification standard for the size of industrial enterprises was first issued in April 1988 by several government agencies, including the State Planning Commission, National Bureau of Statistics, Ministry of Finance, Ministry of Labor, and State Economic Commission. The standard includes detailed specifications based on measurements of output quantity or capacity in technical-quantity terms instead of value terms. The standard is clearly a legacy of the centrally planned economy and is being phased out at present. It now only applies to state-owned industrial enterprises. For private enterprises, the National Bureau of Statistics is using sales as the sole variable in determining enterprise size.

In this study, observations that satisfy one or more of the following screening conditions for industrial enterprises are regarded as unusable, and consequently such enterprises are deleted from the usable sample:

1. Net value of fixed assets $<$ RMB100,000

2. Intermediate inputs $<$ RMB100,000

3. Number of employees $<30$

4. Gross value of industrial inputs at current price $<$ RMB100,000

5. Sales $<$ RMB100,000

6. Total assets $<$ RMB100,000

7. Total assets - liquid assets $<0$

8. Total assets - gross fixed assets $<0$

9. Total assets - net value of fixed assets $<0$

10. Accumulated depreciation - current depreciation $<0$

11. Missing data for total assets, number of employees, gross value of industrial output at current price, net value of fixed assets, or sales 
After the unusable observations are deleted, only about 5 percent or less of the sample enterprises have sales values less than RMB5 million. Tables A.1, A.2, and A.3 show the distribution of usable and unusable observations in the sample by ownership, industry, and region, respectively. Because the unusable observations are evenly distributed across ownership, industry, and region, we believe that excluding them from the usable sample does not create much bias in our analysis.

Table A.4 shows summary statistics for key size variables (i.e., sales, output, assets, liabilities, labor, and value-added) for the sample with the unusable observations removed. Table A.5 shows the same set of size variables at selected percentiles. Table A.6 examines the weight of the sample within the context of the Chinese economy. Clearly, the sample represents an important part of the Chinese economy, and this makes statistical analysis of the sample important and valuable for both policymakers and practitioners.

\section{Appendix 2. List of industry codes and the full industry names}

[06] Coal mining and dressing

[07] Petroleum and natural gas extraction

[08] Ferrous metals mining and dressing

[09] Nonferrous metals mining and dressing

[10] Nonmetal minerals mining and dressing

[12] Logging and transport of timber and bamboo

[13] Food processing

[14] Food production

[15] Beverage production

[16] Tobacco processing

[17] Textile industry

[18] Garments and other fiber products

[19] Leather, furs, down, and related products

[20] Timber, bamboo, cane, palm fiber and straw

[21] Furniture manufacturing

[22] Papermaking and paper products

[23] Printing and record medium reproduction

[24] Cultural, educational, and sports goods

[25] Petroleum processing and coking

[26] Raw chemical materials and chemicals

[27] Medical and pharmaceutical products

[28] Chemical fiber

[29] Rubber products 
[30] Plastic products

[31] Nonmetal mineral products

[32] Smelting and pressing of ferrous metals

[33] Smelting and pressing of nonferrous metals

[34] Metal products

[35] Ordinary machinery manufacturing

[36] Special purposes equipment manufacturing

[37] Transport equipment manufacturing

[40] Electric equipment and machinery

[41] Electronic and telecom equipment

[42] Instruments, cultural, and office machinery

[43] Other manufacturing

[44] Electric power, steam, and hot water

[45] Gas production and supply

[46] Tap water production and supply

\begin{tabular}{|c|c|c|c|c|c|c|c|c|}
\hline & 1995 & 1996 & 1997 & 1998 & 1999 & 2000 & 2001 & 2002 \\
\hline \multicolumn{9}{|l|}{ Data quality } \\
\hline \multicolumn{9}{|l|}{ Poor } \\
\hline Private & 2 & 1 & 2 & 3 & 9 & 14 & 26 & 54 \\
\hline Collective & 60 & 72 & 93 & 66 & 58 & 77 & 86 & 89 \\
\hline Mixed & 23 & 24 & 39 & 73 & 82 & 145 & 178 & 158 \\
\hline Foreign & 41 & 67 & 64 & 43 & 42 & 65 & 65 & 98 \\
\hline Hong Kong, Macau, and Taiwan & 31 & 36 & 34 & 28 & 43 & 59 & 60 & 89 \\
\hline State-owned & 307 & 525 & 583 & 901 & 538 & 626 & 674 & 615 \\
\hline Total & 464 & 725 & 815 & 1,114 & 772 & 986 & 1,089 & 1,103 \\
\hline \multicolumn{9}{|l|}{ Poor (percent) } \\
\hline Private & 28.6 & 6.7 & 5.6 & 1.7 & 2.8 & 2.7 & 2.6 & 4.0 \\
\hline Collective & 1.5 & 1.7 & 2.2 & 1.8 & 1.7 & 2.6 & 3.5 & 4.0 \\
\hline Mixed & 1.8 & 1.7 & 1.9 & 2.4 & 2.2 & 3.2 & 3.1 & 2.5 \\
\hline Foreign & 3.9 & 4.9 & 4.0 & 2.7 & 2.1 & 3.1 & 2.4 & 3.2 \\
\hline Hong Kong, Macau, and Taiwan & 3.2 & 3.1 & 2.7 & 1.9 & 2.7 & 3.7 & 2.6 & 3.4 \\
\hline State-owned & 2.0 & 3.4 & 3.9 & 6.7 & 4.8 & 6.3 & 7.7 & 7.9 \\
\hline Total & 2.0 & 3.1 & 3.4 & 4.8 & 3.5 & 4.5 & 4.7 & 4.7 \\
\hline \multicolumn{9}{|l|}{ Good } \\
\hline Private & 5 & 14 & 34 & 176 & 307 & 498 & 958 & 1,302 \\
\hline Collective & 4,008 & 4,199 & 4,116 & 3,577 & 3,350 & 2,899 & 2,394 & 2,138 \\
\hline Mixed & 1,233 & 1,406 & 2,064 & 2,934 & 3,592 & 4,381 & 5,619 & 6,135 \\
\hline Foreign & 1,000 & 1,305 & 1,525 & 1,579 & 1,924 & 2,048 & 2,610 & 2,935 \\
\hline Hong Kong, Macau, and Taiwan & 936 & 1,115 & 1,222 & 1,454 & 1,524 & 1,552 & 2,211 & 2,495 \\
\hline State-owned & 15,361 & 14,935 & 14,350 & 12,573 & 10,766 & 9,360 & 8,106 & 7,215 \\
\hline Total & 22,543 & 22,974 & 23,311 & 22,293 & 21,463 & 20,738 & 21,898 & 22,220 \\
\hline \multicolumn{9}{|l|}{ Total } \\
\hline Private & 7 & 15 & 36 & 179 & 316 & 512 & 984 & 1,356 \\
\hline Collective & 4,068 & 4,271 & 4,209 & 3,643 & 3,408 & 2,976 & 2,480 & 2,227 \\
\hline Mixed & 1,256 & 1,430 & 2,103 & 3,007 & 3,674 & 4,526 & 5,797 & 6,293 \\
\hline Foreign & 1,041 & 1,372 & 1,589 & 1,622 & 1,966 & 2,113 & 2,675 & 3,033 \\
\hline HK-M-Taiwan & 967 & 1,151 & 1,256 & 1,482 & 1,567 & 1,611 & 2,271 & 2,584 \\
\hline State-owned & 15,668 & 15,460 & 14,933 & 13,474 & 11,304 & 9,986 & 8,780 & 7,830 \\
\hline Total & 23,007 & 23,699 & 24,126 & 23,407 & 22,235 & 21,724 & 22,987 & 23,323 \\
\hline
\end{tabular}


Nonperforming Debts in Chinese Enterprises

Table A.2 Distribution of unusable observations by industry, 1995-2002 (percent)

\begin{tabular}{|c|c|c|c|c|c|c|c|c|}
\hline & 1995 & 1996 & 1997 & 1998 & 1999 & 2000 & 2001 & 2002 \\
\hline [06] Coal mining & 0.4 & 0.3 & 1.0 & 1.0 & 0.7 & 3.2 & 1.8 & 3.7 \\
\hline [07] Petroleum extract & 0.0 & 0.0 & 4.0 & 7.1 & 3.0 & 2.6 & 2.6 & 0.0 \\
\hline [08] Ferrous mining & 0.0 & 0.0 & 0.0 & 0.0 & 0.0 & 2.2 & 7.1 & 0.0 \\
\hline [09] Nonferrous mining & 3.0 & 2.5 & 2.5 & 3.7 & 2.3 & 2.9 & 3.7 & 3.3 \\
\hline [10] Nonmetal mining & 1.4 & 0.9 & 2.8 & 3.4 & 0.0 & 2.8 & 5.1 & 5.4 \\
\hline [12] Timber logging & 0.0 & 0.0 & 0.0 & 0.0 & 1.0 & 4.0 & 4.3 & 5.4 \\
\hline [13] Food processing & 2.3 & 2.7 & 3.7 & 5.0 & 3.6 & 5.4 & 6.9 & 6.5 \\
\hline [14] Food production & 3.6 & 6.6 & 7.3 & 5.9 & 3.9 & 5.8 & 5.4 & 5.7 \\
\hline [15] Beverage & 1.6 & 3.1 & 3.2 & 3.6 & 2.5 & 3.6 & 3.4 & 4.5 \\
\hline [16] Tobacco & 0.7 & 4.2 & 0.0 & 0.0 & 0.0 & 1.4 & 1.4 & 1.4 \\
\hline [17] Textile & 2.5 & 3.0 & 3.8 & 6.0 & 3.8 & 3.8 & 4.4 & 4.8 \\
\hline [18] Garments & 2.8 & 1.5 & 1.8 & 1.6 & 1.3 & 2.0 & 2.0 & 3.1 \\
\hline [19] Leather & 2.6 & 4.5 & 2.8 & 6.3 & 5.0 & 6.5 & 4.9 & 4.3 \\
\hline [20] Timber & 7.4 & 1.5 & 1.3 & 5.2 & 5.3 & 4.9 & 4.1 & 5.4 \\
\hline [21] Furniture & 3.1 & 5.6 & 1.3 & 3.1 & 2.7 & 1.4 & 2.3 & 2.3 \\
\hline [22] Papermaking & 2.6 & 3.3 & 3.0 & 6.7 & 4.4 & 6.1 & 5.1 & 4.6 \\
\hline [23] Printing & 1.1 & 1.3 & 2.5 & 1.3 & 2.3 & 1.6 & 2.3 & 1.6 \\
\hline [24] Cultural & 9.4 & 8.9 & 0.9 & 2.7 & 2.7 & 7.1 & 3.7 & 3.2 \\
\hline [25] Petroleum processing & 0.0 & 2.6 & 2.6 & 0.8 & 0.0 & 2.5 & 3.8 & 5.6 \\
\hline [26] Raw chemicals & 2.4 & 2.7 & 2.2 & 4.2 & 2.5 & 4.3 & 4.9 & 5.1 \\
\hline [27] Medical & 1.6 & 2.4 & 1.8 & 3.9 & 3.4 & 3.8 & 4.1 & 2.9 \\
\hline [28] Chemical fiber & 2.4 & 1.1 & 4.7 & 3.7 & 2.4 & 4.6 & 3.4 & 5.3 \\
\hline [29] Rubber & 4.7 & 3.4 & 3.4 & 4.4 & 3.2 & 3.1 & 4.2 & 6.1 \\
\hline [30] Plastic & 2.6 & 3.6 & 2.9 & 2.1 & 2.8 & 4.4 & 4.6 & 5.1 \\
\hline [31] Nonmetal products & 2.0 & 3.2 & 3.2 & 5.2 & 3.0 & 4.0 & 4.7 & 4.2 \\
\hline [32] Pressing ferrous & 0.4 & 3.5 & 3.2 & 8.5 & 2.6 & 5.4 & 6.8 & 5.7 \\
\hline [33] Pressing nonferrous & 1.1 & 2.3 & 1.4 & 2.2 & 3.2 & 1.9 & 3.0 & 2.8 \\
\hline [34] Metal products & 0.9 & 1.9 & 3.1 & 4.2 & 2.0 & 4.4 & 3.8 & 4.4 \\
\hline [35] Ordinary machinery & 0.5 & 1.0 & 1.9 & 2.2 & 1.8 & 2.6 & 2.4 & 2.6 \\
\hline [36] Special equipment & 0.9 & 1.7 & 1.3 & 1.9 & 2.1 & 2.8 & 3.2 & 3.8 \\
\hline [37] Transport equipment & 1.6 & 2.5 & 2.2 & 3.6 & 2.9 & 3.3 & 3.3 & 2.6 \\
\hline [40] Electric equipment & 1.8 & 2.6 & 1.9 & 3.1 & 1.7 & 3.4 & 2.5 & 3.8 \\
\hline [41] Electronic and telecommunications & 1.8 & 2.4 & 3.0 & 3.0 & 2.1 & 2.9 & 4.3 & 2.8 \\
\hline [42] Instruments & 0.6 & 1.6 & 1.3 & 4.4 & 2.1 & 2.8 & 3.9 & 5.1 \\
\hline [43] Other manufacturing & 3.0 & 4.2 & 3.8 & 2.8 & 2.1 & 3.7 & 3.8 & 5.9 \\
\hline [44] Electric power & 4.7 & 14.2 & 18.6 & 22.8 & 19.5 & 20.3 & 18.4 & 16.8 \\
\hline [45] Gas production & 2.9 & 2.9 & 7.6 & 4.7 & 7.1 & 6.2 & 9.8 & 4.8 \\
\hline [46] Tap water & 1.1 & 1.5 & 1.0 & 1.9 & 1.9 & 1.4 & 2.6 & 1.7 \\
\hline Total & 2.0 & 3.1 & 3.4 & 4.8 & 3.5 & 4.5 & 4.7 & 4.7 \\
\hline
\end{tabular}

Note: See appendix 2 for full industry names corresponding to industry codes. 
Nonperforming Debts in Chinese Enterprises

Table A.3 Distribution of unusable observations by region, 1995-2002 (percent)

\begin{tabular}{lrrrrrrrr}
\hline & $\mathbf{1 9 9 5}$ & $\mathbf{1 9 9 6}$ & $\mathbf{1 9 9 7}$ & $\mathbf{1 9 9 8}$ & $\mathbf{1 9 9 9}$ & $\mathbf{2 0 0 0}$ & $\mathbf{2 0 0 1}$ & $\mathbf{2 0 0 2}$ \\
\hline [11] Beijing & 4.6 & 3.0 & 2.6 & 4.4 & 5.9 & 9.5 & 3.9 & 4.1 \\
[12] Tianjin & 4.4 & 5.9 & 13.9 & 13.1 & 9.3 & 18.2 & 18.5 & 22.3 \\
[13] Hebei & 1.5 & 2.1 & 2.1 & 4.2 & 3.4 & 4.7 & 7.9 & 8.9 \\
[14] Shanxi & 1.6 & 1.9 & 3.1 & 5.1 & 2.5 & 4.4 & 8.1 & 8.6 \\
[15] Inner Mongolia & 1.1 & 5.1 & 7.1 & 7.6 & 7.7 & 9.1 & 9.1 & 9.6 \\
[21] Liaoning & 2.3 & 3.2 & 2.9 & 8.1 & 2.0 & 2.6 & 4.4 & 4.3 \\
[22] Jilin & 2.2 & 6.1 & 7.8 & 11.2 & 12.5 & 10.6 & 11.3 & 10.2 \\
[23] Heilongjiang & 2.7 & 4.3 & 5.5 & 10.2 & 7.9 & 8.2 & 11.4 & 9.0 \\
[31] Shanghai & 5.4 & 5.5 & 5.4 & 3.6 & 1.1 & 1.2 & 0.4 & 1.2 \\
[32] Jiangsu & 0.6 & 0.6 & 1.3 & 0.9 & 0.8 & 1.0 & 0.8 & 1.0 \\
[33] Zhejiang & 0.5 & 1.7 & 1.5 & 1.9 & 4.3 & 4.7 & 4.5 & 3.1 \\
[34] Anhui & 0.8 & 1.2 & 0.4 & 3.7 & 1.8 & 2.7 & 3.5 & 3.6 \\
[35] Fujian & 2.1 & 1.7 & 2.5 & 4.2 & 1.9 & 3.3 & 2.5 & 2.5 \\
[36] Jiangxi & 1.6 & 1.9 & 1.7 & 5.6 & 4.8 & 8.2 & 4.4 & 5.3 \\
[37] Shandong & 1.5 & 2.3 & 2.7 & 2.6 & 2.1 & 2.4 & 2.6 & 2.6 \\
[41] Henan & 1.1 & 7.5 & 7.7 & 8.2 & 5.3 & 8.1 & 10.4 & 12.2 \\
[42] Hubei & 2.6 & 3.3 & 3.6 & 5.7 & 3.2 & 4.0 & 6.1 & 5.0 \\
[43] Hunan & 2.2 & 4.2 & 2.3 & 5.1 & 1.3 & 2.0 & 2.0 & 2.4 \\
[44] Guangdong & 2.8 & 2.5 & 2.2 & 2.7 & 2.7 & 2.9 & 2.5 & 3.2 \\
[45] Guangxi & 0.7 & 5.6 & 1.6 & 2.8 & 0.7 & 2.2 & 1.5 & 2.8 \\
[46] Hainan & 18.1 & 10.7 & 3.5 & 8.1 & 5.8 & 7.6 & 10.9 & 7.8 \\
[50] Sichuan + Chongqing & 1.7 & 2.7 & 1.8 & 5.1 & 4.9 & 6.4 & 5.8 & 3.6 \\
[52] Guizhou & 0.8 & 6.9 & 11.0 & 10.0 & 14.2 & 15.3 & 16.0 & 8.9 \\
[53] Yunnan & 0.9 & 0.0 & 1.2 & 2.9 & 1.1 & 2.6 & 1.5 & 2.3 \\
[54] Tibet + Qinghai + Ningxia & 0.0 & 0.6 & 2.7 & 6.2 & 2.4 & 0.6 & 4.4 & 2.8 \\
[61] Shaanxi & 1.5 & 1.3 & 0.6 & 4.7 & 2.1 & 2.5 & 2.3 & 1.4 \\
[62] Gansu & 1.4 & 1.0 & 6.9 & 7.4 & 8.7 & 9.2 & 8.8 & 10.3 \\
[65] Xinjiang & 1.5 & 1.6 & 1.4 & 3.7 & 0.6 & 4.0 & 2.2 & 1.8 \\
Total & 2.0 & 3.1 & 3.4 & 4.8 & 3.5 & 4.5 & 4.7 & 4.7 \\
\hline
\end{tabular}


Nonperforming Debts in Chinese Enterprises

Table A.4 Summary statistics for sales, output, assets, liabilities, labor, and value-added for the cleaned sample (RMB million)

\begin{tabular}{|c|c|c|c|c|c|c|c|}
\hline & $\begin{array}{l}\text { Number of } \\
\text { enterprises }\end{array}$ & Mean & $\begin{array}{l}\text { Standard } \\
\text { deviation }\end{array}$ & Median & Minimum & Maximum & Sum \\
\hline \multicolumn{8}{|l|}{ Sales } \\
\hline 1995 & 22,543 & 136 & 630 & 45 & 0.109 & 39,930 & $3,071,530$ \\
\hline 1996 & 22,974 & 144 & 681 & 44 & 0.100 & 43,738 & $3,308,847$ \\
\hline 1997 & 22,957 & 155 & 761 & 44 & 0.103 & 50,760 & $3,560,393$ \\
\hline 1998 & 22,293 & 163 & 772 & 44 & 0.101 & 50,611 & $3,629,511$ \\
\hline 1999 & 21,463 & 188 & 871 & 50 & 0.107 & 61,211 & $4,032,923$ \\
\hline 2000 & 20,738 & 234 & 1,219 & 57 & 0.112 & 92,279 & $4,843,396$ \\
\hline 2001 & 21,898 & 257 & 1,213 & 63 & 0.109 & 78,984 & $5,624,020$ \\
\hline 2002 & 22,220 & 292 & 1,329 & 69 & 0.101 & 72,843 & $6,495,292$ \\
\hline Total & 177,086 & 195 & 966 & 51 & 0.100 & 92,279 & $34,565,913$ \\
\hline \multicolumn{8}{|c|}{$\begin{array}{l}\text { Gross value of } \\
\text { industrial output }\end{array}$} \\
\hline 1995 & 22,543 & 136 & 616 & 46 & 0.101 & 40,214 & $3,073,253$ \\
\hline 1996 & 22,974 & 147 & 685 & 48 & 0.130 & 44,349 & $3,378,619$ \\
\hline 1997 & 22,957 & 157 & 762 & 48 & 0.113 & 51,693 & $3,607,608$ \\
\hline 1998 & 22,293 & 165 & 767 & 48 & 0.100 & 51,646 & $3,681,858$ \\
\hline 1999 & 21,463 & 190 & 874 & 54 & 0.106 & 63,918 & $4,068,673$ \\
\hline 2000 & 20,738 & 230 & 1,171 & 61 & 0.150 & 92,617 & $4,775,290$ \\
\hline 2001 & 21,898 & 255 & 1,177 & 67 & 0.140 & 79,422 & $5,573,291$ \\
\hline 2002 & 22,220 & 288 & 1,275 & 71 & 0.100 & 73,633 & $6,388,539$ \\
\hline Total & 177,086 & 195 & 943 & 54 & 0.100 & 92,617 & $34,547,132$ \\
\hline \multicolumn{8}{|c|}{ Total assets } \\
\hline 1995 & 22,543 & 229 & 1,047 & 79 & 0.829 & 65,931 & $5,161,722$ \\
\hline 1996 & 22,974 & 256 & 1,199 & 85 & 0.831 & 75,366 & $5,872,942$ \\
\hline 1997 & 22,957 & 291 & 1,388 & 92 & 0.701 & 83,704 & $6,690,180$ \\
\hline 1998 & 22,293 & 329 & 1,522 & 99 & 0.701 & 90,322 & $7,323,630$ \\
\hline 1999 & 21,463 & 369 & 1,684 & 105 & 1.350 & 91,485 & $7,918,937$ \\
\hline 2000 & 20,738 & 397 & 1,763 & 111 & 1.770 & 85,791 & $8,239,931$ \\
\hline 2001 & 21,898 & 420 & 1,846 & 113 & 0.741 & 86,018 & $9,196,855$ \\
\hline 2002 & 22,220 & 446 & 1,882 & 115 & 0.835 & 85,809 & $9,909,926$ \\
\hline Total & 177,086 & 341 & 1,564 & 98 & 0.701 & 91,485 & $60,314,123$ \\
\hline \multicolumn{8}{|c|}{ Total liabilities } \\
\hline 1995 & 22,543 & 146 & 595 & 56 & 0.028 & 29,785 & $3,285,112$ \\
\hline 1996 & 22,974 & 161 & 658 & 60 & 0.016 & 27,652 & $3,706,920$ \\
\hline 1997 & 22,957 & 183 & 788 & 64 & 0.016 & 31,269 & $4,201,084$ \\
\hline 1998 & 22,293 & 207 & 859 & 69 & 0.098 & 33,133 & $4,609,115$ \\
\hline 1999 & 21,463 & 224 & 895 & 71 & 0.022 & 32,958 & $4,804,740$ \\
\hline 2000 & 20,738 & 239 & 957 & 74 & 0.010 & 46,409 & $4,962,981$ \\
\hline 2001 & 21,898 & 243 & 908 & 72 & 0.001 & 33,647 & $5,328,350$ \\
\hline 2002 & 22,220 & 258 & 990 & 71 & 0.016 & 43,050 & $5,723,794$ \\
\hline Total & 177,086 & 207 & 840 & 66 & 0.001 & 46,409 & $36,622,096$ \\
\hline \multicolumn{8}{|c|}{ Number of employees } \\
\hline 1995 & 22,543 & 1,696 & 5,215 & 877 & 30 & 254,078 & $38,223,099$ \\
\hline 1996 & 22,974 & 1,633 & 4,908 & 823 & 30 & 197,048 & $37,513,117$ \\
\hline 1997 & 22,957 & 1,593 & 4,719 & 793 & 30 & 193,076 & $36,581,069$ \\
\hline 1998 & 22,293 & 1,502 & 4,482 & 715 & 30 & 193,110 & $33,490,764$ \\
\hline 1999 & 21,463 & 1,428 & 4,401 & 654 & 30 & 194,410 & $30,656,548$ \\
\hline 2000 & 20,738 & 1,361 & 3,947 & 620 & 30 & 161,654 & $28,225,561$ \\
\hline 2001 & 21,898 & 1,237 & 3,599 & 560 & 30 & 147,722 & $27,079,491$ \\
\hline 2002 & 22,220 & 1,189 & 3,560 & 520 & 30 & 137,962 & $26,426,284$ \\
\hline Total & 177,086 & 1,458 & 4,404 & 701 & 30 & 254,078 & $258,195,933$ \\
\hline \multicolumn{8}{|c|}{ Reported value-added } \\
\hline 1995 & 22,543 & 43 & 332 & 11 & -424 & 32,912 & 958,256 \\
\hline 1996 & 22,974 & 44 & 348 & 11 & $-3,241$ & 34,809 & $1,016,728$ \\
\hline 1997 & 22,957 & 47 & 382 & 12 & $-6,738$ & 39,565 & $1,080,121$ \\
\hline 1998 & 22,293 & 51 & 398 & 12 & $-5,939$ & 41,525 & $1,131,106$ \\
\hline 1999 & 21,463 & 60 & 479 & 14 & $-1,954$ & 53,645 & $1,288,589$ \\
\hline 2000 & 20,738 & 73 & 690 & 16 & $-12,140$ & 79,063 & $1,520,978$ \\
\hline 2001 & 21,898 & 80 & 660 & 18 & $-1,796$ & 78,355 & $1,741,547$ \\
\hline 2002 & 22,220 & 91 & 652 & 20 & $-2,339$ & 72,057 & $2,012,908$ \\
\hline Total & 177,086 & 61 & 510 & 14 & $-12,140$ & 79,063 & $10,750,232$ \\
\hline
\end{tabular}

REGULAR

1 LINE LONG 
Nonperforming Debts in Chinese Enterprises

Table A.5 Size of sales, output, assets, liabilities, labor, and value-added at selected percentiles for the cleaned sample (RMB million)

\begin{tabular}{|c|c|c|c|c|c|c|c|}
\hline & \multicolumn{7}{|c|}{ Percentiles } \\
\hline & 5 & 10 & 25 & 50 & 75 & 90 & 95 \\
\hline \multicolumn{8}{|l|}{ Sales } \\
\hline 1995 & 6 & 10 & 20 & 45 & 101 & 233 & 418 \\
\hline 1996 & 5 & 9 & 19 & 44 & 102 & 245 & 438 \\
\hline 1997 & 4 & 8 & 19 & 44 & 105 & 264 & 488 \\
\hline 1998 & 4 & 7 & 18 & 44 & 107 & 286 & 530 \\
\hline 1999 & 6 & 9 & 21 & 50 & 125 & 325 & 614 \\
\hline 2000 & 6 & 10 & 23 & 57 & 146 & 387 & 739 \\
\hline 2001 & 6 & 11 & 25 & 63 & 162 & 444 & 838 \\
\hline 2002 & 6 & 11 & 27 & 69 & 181 & 505 & 983 \\
\hline \multicolumn{8}{|c|}{ Gross value of industrial output } \\
\hline 1995 & 7 & 10 & 22 & 46 & 104 & 236 & 403 \\
\hline 1996 & 6 & 10 & 21 & 48 & 110 & 250 & 440 \\
\hline 1997 & 5 & 9 & 21 & 48 & 112 & 266 & 489 \\
\hline 1998 & 5 & 9 & 20 & 48 & 115 & 288 & 536 \\
\hline 1999 & 7 & 11 & 24 & 54 & 131 & 333 & 606 \\
\hline 2000 & 6 & 11 & 25 & 61 & 151 & 388 & 730 \\
\hline 2001 & 7 & 12 & 27 & 67 & 169 & 444 & 836 \\
\hline 2002 & 7 & 12 & 29 & 71 & 186 & 505 & 956 \\
\hline \multicolumn{8}{|c|}{ Total assets } \\
\hline 1995 & 22 & 28 & 44 & 79 & 167 & 378 & 676 \\
\hline 1996 & 23 & 29 & 46 & 85 & 180 & 414 & 745 \\
\hline 1997 & 22 & 29 & 48 & 92 & 198 & 474 & 888 \\
\hline 1998 & 23 & 30 & 50 & 99 & 218 & 538 & 1,007 \\
\hline 1999 & 24 & 32 & 54 & 105 & 239 & 603 & 1,144 \\
\hline 2000 & 23 & 31 & 54 & 111 & 259 & 672 & 1,304 \\
\hline 2001 & 22 & 31 & 54 & 113 & 271 & 725 & 1,445 \\
\hline 2002 & 21 & 30 & 54 & 115 & 282 & 775 & 1,589 \\
\hline \multicolumn{8}{|c|}{ Total liabilities } \\
\hline 1995 & 12 & 17 & 29 & 56 & 115 & 245 & 424 \\
\hline 1996 & 12 & 18 & 31 & 60 & 125 & 268 & 471 \\
\hline 1997 & 12 & 18 & 33 & 64 & 137 & 301 & 542 \\
\hline 1998 & 12 & 19 & 34 & 69 & 151 & 345 & 641 \\
\hline 1999 & 12 & 18 & 35 & 71 & 160 & 381 & 709 \\
\hline 2000 & 11 & 18 & 35 & 74 & 169 & 412 & 784 \\
\hline 2001 & 9 & 16 & 32 & 72 & 170 & 429 & 848 \\
\hline 2002 & 9 & 15 & 31 & 71 & 176 & 459 & 910 \\
\hline \multicolumn{8}{|c|}{ Number of employees } \\
\hline 1995 & 211 & 306 & 520 & 877 & 1,515 & 2,858 & 4,631 \\
\hline 1996 & 186 & 271 & 475 & 823 & 1,457 & 2,806 & 4,584 \\
\hline 1997 & 168 & 248 & 445 & 793 & 1,429 & 2,767 & 4,595 \\
\hline 1998 & 141 & 208 & 388 & 715 & 1,340 & 2,656 & 4,429 \\
\hline 1999 & 126 & 187 & 348 & 654 & 1,257 & 2,566 & 4,258 \\
\hline 2000 & 116 & 173 & 323 & 620 & 1,208 & 2,497 & 4,143 \\
\hline 2001 & 103 & 150 & 288 & 560 & 1,129 & 2,332 & 3,815 \\
\hline 2002 & 92 & 134 & 260 & 520 & 1,079 & 2,257 & 3,778 \\
\hline \multicolumn{8}{|c|}{ Reported value-added } \\
\hline 1995 & -2 & 1 & 4 & 11 & 26 & 64 & 121 \\
\hline 1996 & -2 & 0 & 4 & 11 & 29 & 69 & 131 \\
\hline 1997 & -2 & 0 & 4 & 12 & 30 & 74 & 141 \\
\hline 1998 & -2 & 1 & 4 & 12 & 31 & 80 & 159 \\
\hline 1999 & 0 & 2 & 5 & 14 & 37 & 95 & 183 \\
\hline 2000 & 0 & 2 & 6 & 16 & 43 & 115 & 215 \\
\hline 2001 & 1 & 2 & 7 & 18 & 49 & 131 & 247 \\
\hline 2002 & 0 & 2 & 7 & 20 & 54 & 147 & 289 \\
\hline
\end{tabular}


Nonperforming Debts in Chinese Enterprises

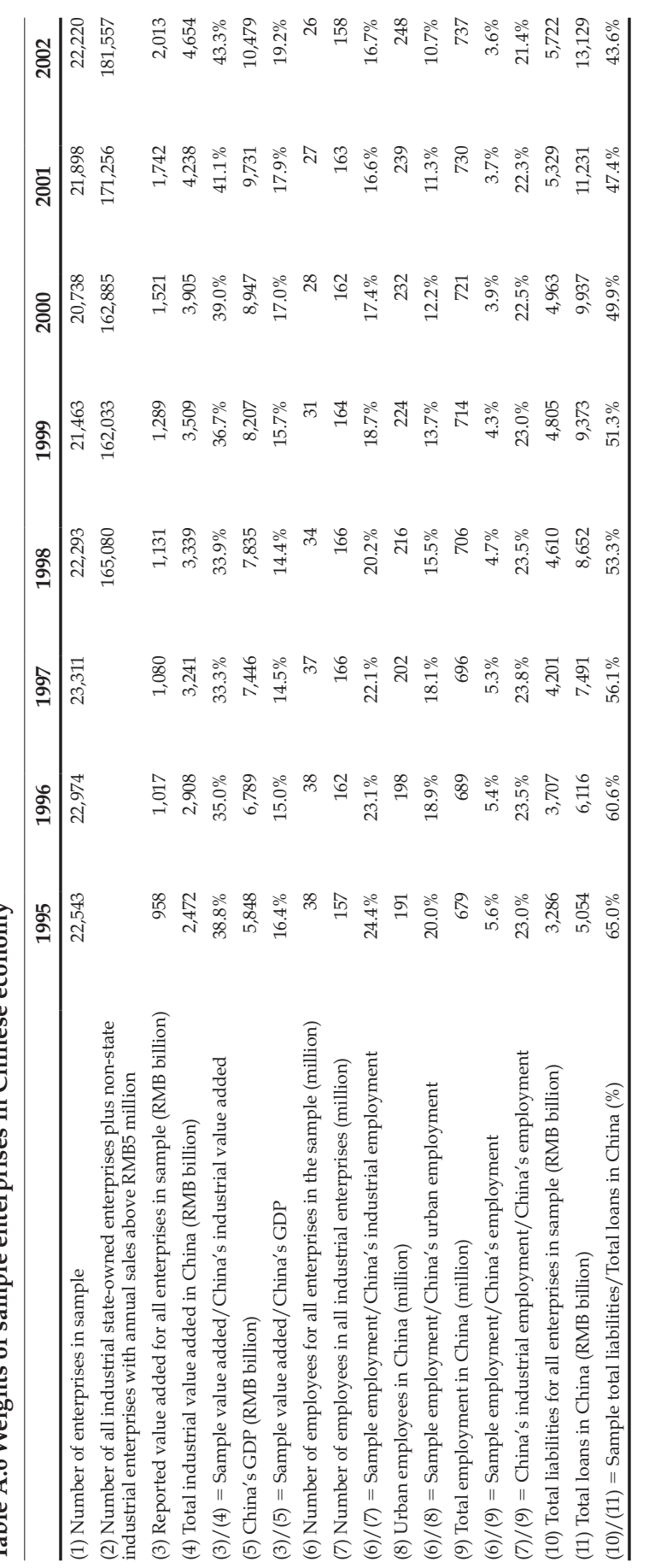

REGULAR

1 LINE LONG 
Nonperforming Debts in Chinese Enterprises

\section{References}

Anderson, Jonathan. 2005. How to Think about China (Part 3): Which Way Out for the Banking System? Asian Economic Perspectives, 9 May. UBS Investment Research.

Cai, Hongbin, Qiao Liu, and Geng Xiao. 2005. Does Competition Encourage Unethical Behavior? The Case of Corporate Profit Hiding in China. Hong Kong Institute of Economics and Business Strategy Working Paper no. 1126. Hong Kong: The University of Hong Kong.

China Banking Regulatory Commission (CBRC). Statistics. Available at http:/ /www.cbrc .gov.cn

Liu, Qiao, and Geng Xiao. 2004. Look Who Are Disguising Profits: An Application to Chinese Industrial Firms. Hong Kong Institute of Economics and Business Strategy Working Paper no. 1095. Hong Kong: The University of Hong Kong.

Xiao, Geng. 2005. What Is Special about Enterprise Performance in North-East People's Republic of China? Dynamics of Privatization, Profitability and Productivity during the Reform Era. Hong Kong Institute of Economics and Business Strategy Working Paper no. 1133. Hong Kong: The University of Hong Kong.

Xiao, Geng, and Zhengge Tu. 2005. China's Industrial Productivity Revolution: A Stochastic Frontier Production Function Analysis of China's Large and Medium-Sized Industrial Enterprises during 1995-2002. Paper presented at the Western Economic Association International and Hong Kong Economic Association conference, 15 January, Hong Kong. 